\title{
Aza-Prins Reaction in the Synthesis of Natural Products and
} Analogues

\author{
B. V. Subba Reddy, ${ }^{*[a]}$ Preethi Narayanan Nair, ${ }^{\left[{ }^{[a]}\right.}$ Aneesh Antony, ${ }^{[a]}$ Claudia Lalli, ${ }^{*[b]}$ and René Grée ${ }^{\star[b]}$
}

\begin{abstract}
Classical Prins cyclization reaction is one of the most studied reactions during the last two decades and it has found many applications in the key steps of natural product syntheses, especially for those having pyrans and related structures in their core skeleton. Nitrogen-based version of the Prins reaction, aza-Prins cyclization, found its own relevance in organic synthesis owing to the fact that it gives direct access to piperidines which are even more widespread in natural products and in drugs. Even though the potential scope of the reaction is very vast and despite it afforded significant progress in the synthesis of various aza heterocycles, its applications in the field of natural product synthesis is by far under developed compared to the classical Prins reaction. A compilation of the applications of aza-Prins reaction in the preparation of natural products and selected analogues, especially the molecules of potential biological interest, is presented by giving emphasis on the key role of this reaction during the total synthesis of these products.
\end{abstract}

\section{Introduction}

The Prins cyclization reaction (Scheme 1) is one of the most powerful methods for generating oxygen-containing heterocycles through concomitant carbon-heteroatom and carbon-carbon bond formation, showing great potential in the synthesis of natural and/or bioactive compounds. ${ }^{1}$ The aza-Prins cyclization is the nitrogen version of the reaction, which permits a rapid access to aza heterocycles. ${ }^{2}$ This reaction is mediated by a variety of Brønsted and Lewis acids and further, a large number of nucleophiles, compatible with the acid reaction conditions, have also been used. Various types of solvents have been employed as well, including more recently ionic liquids. The mechanism of this reaction has been also well investigated, including by high level computational studies. The classical azaPrins, as well as three more recent variants of this reaction considered in this review, are indicated in Figure 1.

[a] P. N. Nair, A. Antony, Basi V. Subba Reddy

Centre for Semio Chemicals

CSIR-Indian Institute of Chemical Technology, Hyderabad, India e-mail: basireddy@iict.res.in

[b] R. Grée

Université de Rennes

Institut des Sciences Chimiques de Rennes, CNRS UMR 6226

Avenue du General Leclerc, 35042 Rennes-Cedex, France

e-mail:rene.gree@univ-rennes1.fr

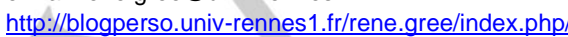

C. Lalli

Université de Rennes 1

Institut des Sciences Chimiques de Rennes, CNRS UMR 6226

Avenue du Pr. Léon Bernard, 35043 Rennes-Cedex, France

e-mail: claudia.Ialli@univ-rennes1.fr

http://blogperso.univ-rennes1.fr/claudia.lalli/

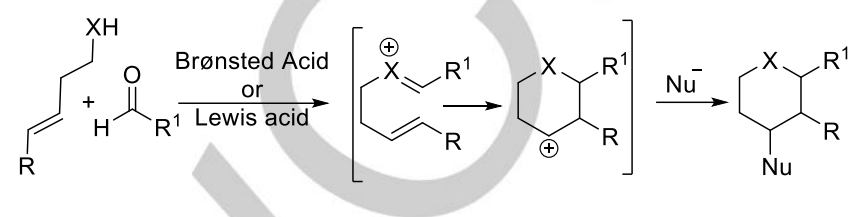

Scheme 1. Prins cyclization $(X=O)$ and related reactions aza-Prins $(X=N-P G)$ and thia Prins $(\mathrm{X}=\mathrm{S})$.

The aza-Prins gives a direct access, often with a good stereocontrol, to the piperidine skeleton with introduction of the nucleophile in position 4 (Figure 1, a). On the other hand, the alkyne aza-Prins provides similar molecules but with a double bond in position 3-4 (Figure 1, b), while in the case of aza-silylPrins, the reaction occurs with loss of the silicon group and 3,4dehydropiperidines are obtained directly (Figure 1, c). Finally, the aza-acyliminium-Prins affords piperidines, equivalent to the first series, but in an $\mathrm{N}$-protected format (Figure 1, d). It is possible to combine this acyliminium version with the previous ones, as demonstrated in this review. Since the piperidine core is abundant in natural products, as well as in various types of bioactive non-natural molecules, the aza-Prins reaction has been already often used for the preparation of this type of products. To date and to the best of our knowledge, there is no review in the literature devoted specifically to the aza-Prins cyclization. ${ }^{1 d}$ Therefore, this publication is focused on the comprehensive compilation of the recent applications of the azaPrins cyclization as key step in the synthesis of natural products and/or biologically relevant compounds. We will consider first the simplest derivatives with a piperidine core and then more complex molecules with bicyclic structures and finally polyheterocycles. In each case, we will highlight the impact of the aza-Prins cyclization on the total synthesis of corresponding molecules. 
<smiles>C=CCC([Tl])NPC=O</smiles>

$\stackrel{\text { Acid cat. }}{\longrightarrow}$

$\mathrm{Nu}$

Aza-Prins<smiles>[R]C(CC#C)NP</smiles>

Aza-alkyne-Prins

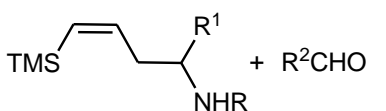

Aza-silyl-Prins<smiles>[R]C(CC=C)NC(=O)[OH2+]</smiles>

$\mathrm{Nu}$

Aza-acyliminium-Prins

\section{Acid cat.}

$\mathrm{Nu}$<smiles>[R]C1CC([N])CC([R])N1P</smiles>

a)<smiles>[R]C1C=C([N])CC([R])N1P</smiles><smiles>[R]C1CCCC1[R]</smiles>
d)<smiles>[R7]C(C)N(C)C([R7])CC</smiles>
COR
Aneesh Antony was born on 1984 in North M.Sc. degree in chemistry from Mahathma Gandhi University, Kottayam, Kerala. He is currently doing Ph.D under the supervision of Dr. B. V. Subba Reddy at Indian Institute of Chemical Technology, Hyderabad. His major focus area of interest in research is development of novel methodologies in asymmetric synthesis. Paravoor, Kerala, India. He obtained his

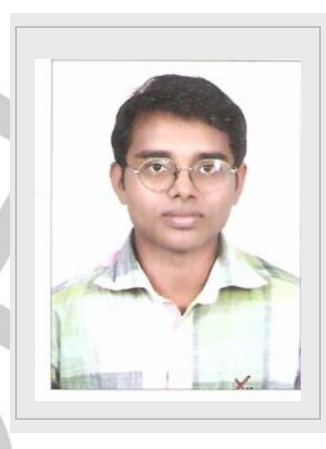

Dr. Claudia Lalli received her PhD degree in 2009 from the University of Florence (Italy) under the supervision of Pr. A. Guarna, and Dr. A. Trabocchi. She joined the ICSN in Gifsur-Yvette (France) as postdoctoral fellow first with Pr. J. Zhu and then in Dr. G.

Masson's group. Her work was mainly focused on multicomponent reactions and on new chiral phosphoric acid catalyzed enantioselective transformations. She has been appointed as Chargé de Recherche CNRS in 2012, at the University of Rennes 1 where she develops new methods in asymmetric Prins processes and organometallic catalysis.

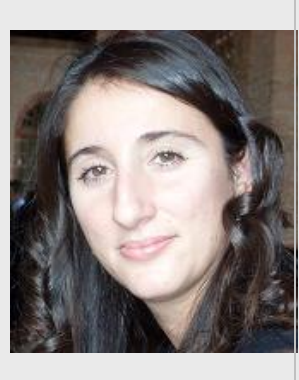

Figure 1. Aza-Prins and related reactions.
Dr René Grée received his PhD from the University of Rennes with Pr R. Carrié. After a post-doc in US with $\operatorname{Pr}$ L. A. Paquette, he started independent research in various areas of organic synthesis. His actual topics of research include: - organometallic chemistry and synthetic applications; fluorine chemistry; - medicinal chemistry (cancer, CNS disorders). He is currently Emeritus CNRS Director of Research at the Institute for Chemical Sciences in Rennes.
Dr. B. V. Subba Reddy was born in Andhra Pradesh and obtained his Ph.D. from the years of post-doc study with Prof. E. J. Corey at Harvard University, he returned to India and took up a scientist position at IICT in June 2006 and currently occupying the position of Head of the Department, Centre for Semio Chemicals, CSIR-IICT, Hyderabad. He has made major contribution in the field of novel method developments in Prins and aza Prins cyclization reactions. His other areas of expertise include asymmetric synthesis, sugar chemistry, and synthesis of biologically active moieties.

Preethi Narayanan Nair was born on 1991 in Kothamangalam, Kerala, India. She completed her M.Sc. degree in chemistry in the year 2013 from Mahathma Gandhi University, Kottayam, Kerala. She is currently doing her research works under the supervision of Dr. B. V. Subba Reddy at Indian Institute of Chemical Technology, Hyderabad. Her major focus area of interest in research is the development of novel methodologies in Prins and aza-Prins cyclization reactions.

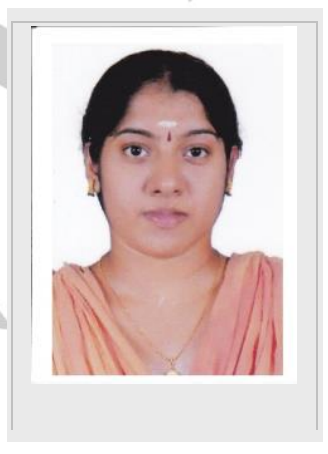

\section{Synthesis of natural products and bioactive molecules}

\subsection{Piperidine derivatives}

We will start by describing the synthesis of the natural products showing the simplest architecture, ie the piperidine or tetrahydropyridine cores. In that case, the preparation of natural products or biologically active compounds comes as a direct application of the synthetic methodology. In this context Dobbs and co-workers reported a novel aza-silyl-Prins cyclization between an aldehyde and a silylated homoallylic amine in the presence of $\mathrm{InCl}_{3}$ as mild Lewis acid. ${ }^{3}$ This methodology exhibited a perfect diastereocontrol since when a substituent was introduced at the $\alpha$-carbon atom to the nitrogen atom, only the 2,6-trans-substituted product was obtained. To illustrate the 
synthetic utility of this reaction, expedient syntheses of (-)Solenopsin A 6 and (+)-epi-Dihydropinidine 7, drugs candidates for the treatment of Alzheimer's disease, were successfully carried out. The key step in both cases was a one-pot multicomponent aza-silyl-Prins condensation involving the $\mathrm{N}$-benzyl silylated secondary amine 1. In a first attempt the syntheses were performed with racemic $\mathbf{1}$ and aldehydes $\mathbf{2}$ and $\mathbf{3}$ which gave the trans-substituted tetrahydropyridines 4 , in $72 \%$ yield, and 5 , in $58 \%$ yield respectively. Deprotection of the benzyl group together with the concomitant reduction of the double bond proceeded quantitatively and completed the synthesis of the target molecules Solenopsin A and epi-Dihydropinidine (Scheme 2). The enantiopure version of the syntheses was then achieved by using each enantiomer of amine 1 . Latter intermediates were obtained through a short sequence starting by the ring opening of $(R)-(+)$ or $(S)-(-)$ propylene oxide with trimethylsilylacetylene and $\mathrm{BF}_{3} \cdot \mathrm{Et}_{2} \mathrm{O}$.

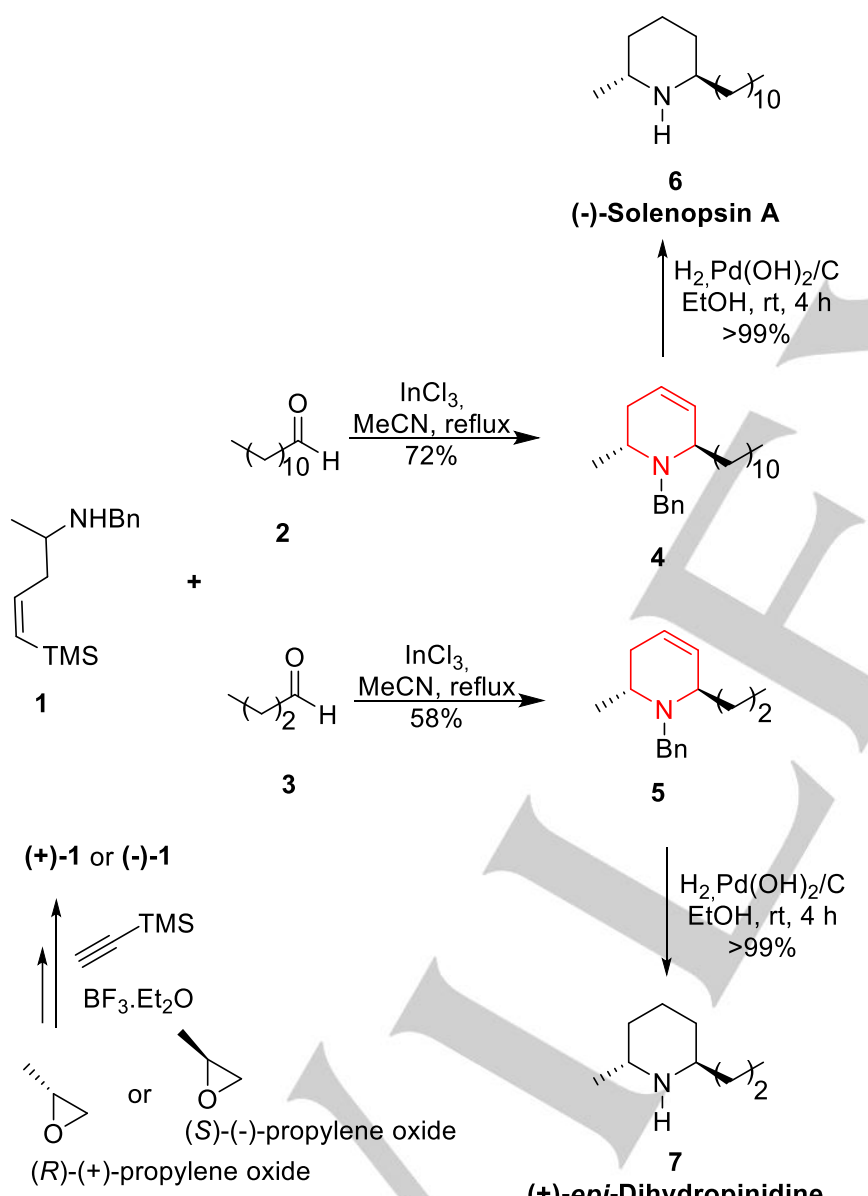

(+)-epi-Dihydropinidine

Scheme 2. Solenopsin A and epi-Dihydropinidine synthesis via aza-silyl-Prins cyclization.

As an extension of this work the same group reported a rapid access to trifluoromethylated piperidines, with a large variety of substituents, molecules which are of great interest in the synthetic and medicinal chemistry field. ${ }^{4}$ Therefore the authors prepared the vinylsilane 8 with a $\mathrm{CF}_{3}$ group on the carbon- $\alpha$ to the nitrogen, as a $E: Z=1: 1$ mixture. This homoallylic amine undergoes aza-silyl-Prins cyclization with aliphatic aldehydes to afford tetrahydropyridines $\mathbf{9}$ in modest yields and as trans major or unique diastereomers (Scheme 3, a). Moreover they observed that the $Z$-alkene was always consumed during the reaction while the $E$-alkene was recovered from the reaction mixture. Further manipulations on the compound $\mathbf{1 0}$ obtained from ethyl glyoxylate consisted in the bishydroxylation in the presence of $\mathrm{NMO}$ and catalytic amounts of osmium tetroxide, followed by acetylation to complete the synthesis of $\mathrm{CF}_{3^{-}}$ containing pipecolate derivatives such as 11 (Scheme 3, b).

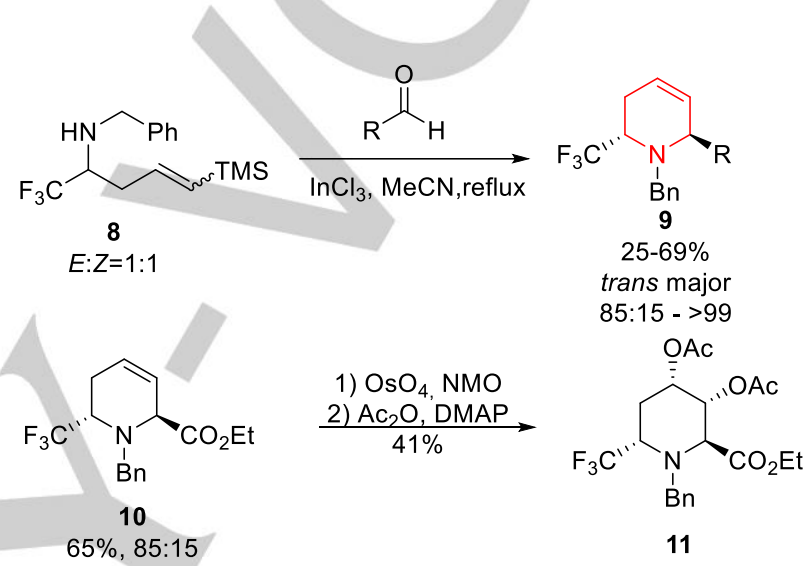

Scheme 3. Synthesis of $\mathrm{CF}_{3}$-containing pipecolate derivatives via aza-silylPrins cyclization.

In an attempt to solve the problem of the deprotection of the tosyl group, very often present on the final piperidine products, the group of Martín and Padrón studied the reactivity of $\mathrm{N}$-nosyl and $\mathrm{N}$-mesyl homoallyl and homopropargyl amines in the presence of $\mathrm{Fe}$ (III) salts. ${ }^{5}$ In this context they developed a short synthesis, in racemic form, of the alkaloid Coniine, used in ancient Greece as poison. They designed two different three steps routes (Scheme 4). For the first approach an alkyne azaPrins cyclization of homopropargyl(mesyl)amine 12 with butanal 3 was evoked. Stoichiometric amount of $\mathrm{FeCl}_{3}$ were required to promote the reaction and recover the tetrahydropyridine 14 in $85 \%$ yield. Hydrogenation by treatment with $\mathrm{Pd}(\mathrm{OH})_{2} / \mathrm{C}$ and ammonium formate as $\mathrm{H}_{2}$ source delivered the piperidine $\mathbf{1 6}$ in $90 \%$ yield. The second approach reposed on a classical azaPrins with homoallyl(mesyl)amine $\mathbf{1 3}$ with butanal $\mathbf{3}$, in the presence of $\mathrm{FeCl}_{3} / \mathrm{TMSCl}$ as catalytic system. The 4-Clpiperidine 15 was recovered in $72 \%$ yield and the chlorine atom removed in the presence of $\mathrm{Bu}_{3} \mathrm{SnH}$ and $\mathrm{AIBN}$, to get the same intermediate 16 in $90 \%$ yield. The desired Coniine 17 was obtained in $85 \%$ yield after deprotection of the mesyl group with Red-Al in toluene. 


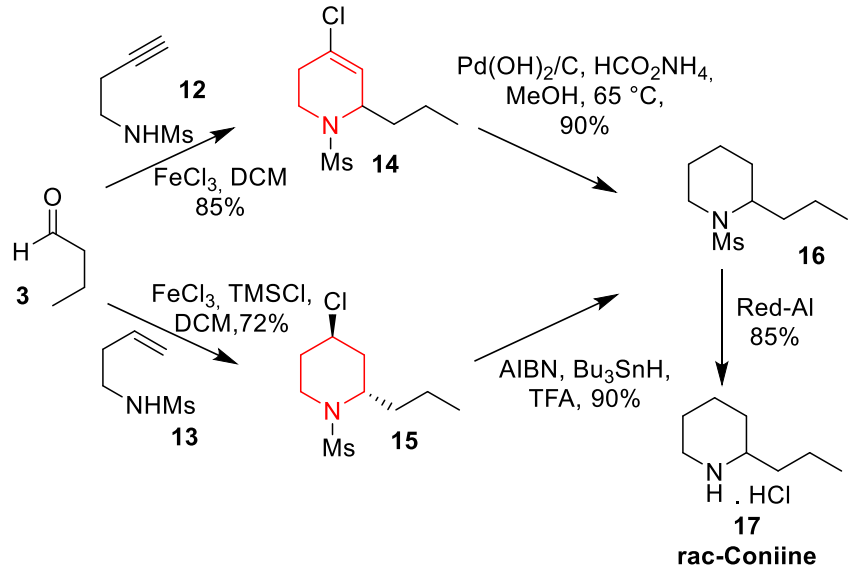

Scheme 4. Alkyne aza-Prins and classical aza-Prins cyclizations for the synthesis of rac-Coniine.

Thomassigny and co-workers reported a very short synthesis of the tobacco alkaloid Anabasine 21, as an extension of the method they developed for the aza-Prins cyclization of pyridine carbaldehydes. ${ }^{6}$ The two step sequence involved an $\operatorname{In}(\mathrm{OTf})_{3^{-}}$ promoted aza-Prins reaction between the homoallylic amine $\mathbf{1 9}$ and the pyridine-3-carbaldehyde 18, affording a mixture of the two regioisomers of the pyridyl-dehydropiperidine 20 in $44 \%$ yield. A final selective hydrogenation with $\mathrm{PtO}_{2}$ and $\mathrm{H}_{2}$ ended up with the racemic target molecule in 93\% yield (Scheme 5).

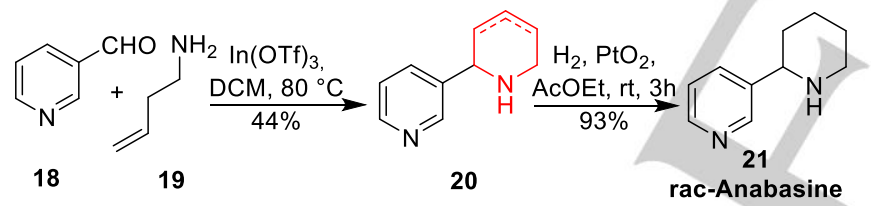

Scheme 5. Aza-Prins cyclization of pyridine carbaldehydes: synthesis of racAnabasine.

Subba Reddy and co-workers reported an efficient synthesis of several piperidine and indolizidine natural products such as $( \pm)$ Coniine 17, ( \pm )-Pipecolic acid 26, ( \pm )-Hydroxypipecolic acid 30 ,

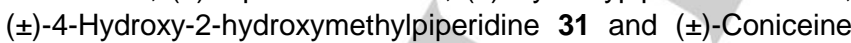
27. The common strategy involved a highly diastereoselective aza-Prins cyclization to construct the key 4-iodo 25 (Scheme 6) and 4-hydroxy piperidine 29 cores (Scheme 7) of these alkaloids. ${ }^{7}$ The iodo piperidines 25 were obtained by using $\mathrm{Gal}_{3}$ and $\mathrm{I}_{2}$ as promoters of the aza-Prins process between homoallylamine 22 and aldehydes 23, 24 and 3 in 85\%-92\% yields. Further manipulations of the ring substituents (2-3 steps) completed the route to targets molecules (Scheme 6). An indolizidine core was also obtained by intramolecular cyclization of the $N$ atom onto the leaving group in terminal position of the side chain to give $( \pm$ )-Coniceine 27 . This molecule is known as a blocker for nicotinic receptor.

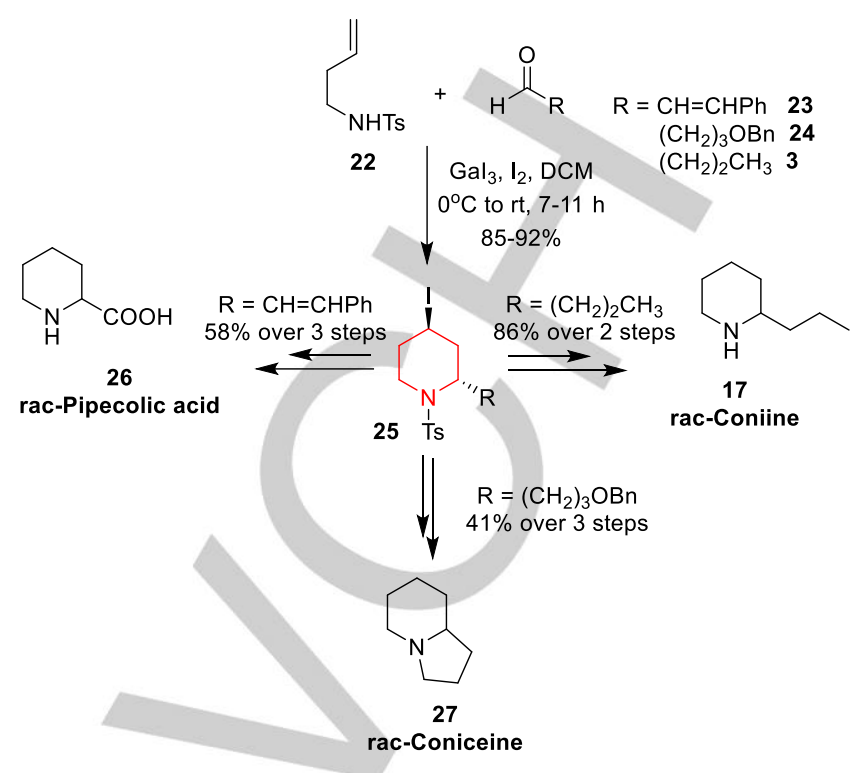

Scheme 6. Synthesis of $( \pm)$-Coniine, $( \pm)$-Pipecolic acid and $( \pm)$-Coniceine via a $\mathrm{Gal}_{3} / \mathrm{l}_{2}$ mediated aza-Prins cyclization.

On the other hand, the hydroxy piperidines $\mathbf{2 9}$ were synthesized by a phosphomolybdic acid (PMA)-catalyzed aza-Prins cyclization between homoallylamine 22 and aldehydes 23 and 28 in $85 \%$ and $65 \%$ yield respectively. Starting with 29a, oxidative cleavage of the olefin to give the corresponding carboxylic acid and deprotection of the tosyl group delivered racemic Hydroxypipecolic acid 30 in 54\% yield over 2 steps, while racemic 4-Hydroxy-2-hydroxymethyl-piperidine $\mathbf{3 1}$ was obtained from $29 \mathrm{~b}$ by a simple deprotection of the Ts group in $70 \%$ yield (Scheme 7 ).

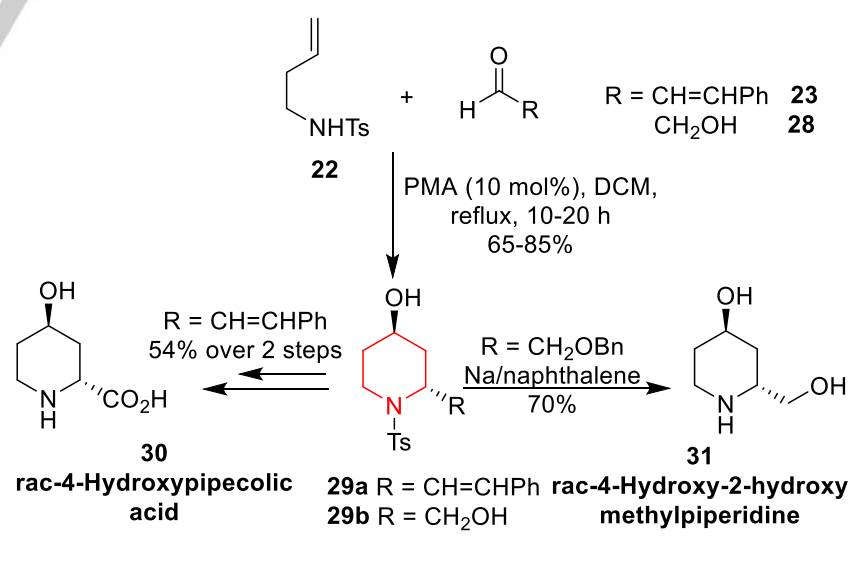

Scheme 7. ( \pm )-Hydroxypipecolic acid and ( \pm )-4-Hydroxy-2 hydroxymethylpiperidine synthesis via a PMA promoted aza-Prins cyclization.

With the aim of synthesizing new antibiotics against drug resistant bacteria, Ichikawa's group designed simplified analogues of a nucleoside antibiotic, caprazamycin A 32 (Scheme 8). ${ }^{8}$ The $\mathrm{N}$ atom in the C-6' position is critical for the 
activity of the natural product, thus the authors thought to replace the central diazepanone core with a piperidine ring. A three component aza-Prins-Ritter sequence seemed to be the most step economic way to have access to piperidinylaminoribosyluridines. The aldehydes $\mathbf{3 3}$ and $\mathbf{3 4}$, diastereomers at the 5 ' stereocenter, were synthesized and reacted with $\mathrm{N}-\mathrm{Cbz}$ homoallylic amine 35 in the presence of $\mathrm{TfOH}$ in acetonitrile at $0{ }^{\circ} \mathrm{C}$ to give the desired uridine derivatives containing the piperidine core. Aldehyde $\mathbf{3 3}$ furnished three diastereomers in $53 \%$ overall yield and in a ratio 7:2:1 but only $\mathbf{3 6}$ and $\mathbf{3 7}$ were characterized and used for the next steps. On the other hand, from aldehyde $\mathbf{3 4}$ only compounds $\mathbf{3 8}$ and $\mathbf{3 9}$ were obtained in $22 \%$ and $19 \%$ yield respectively (Scheme 8 ).

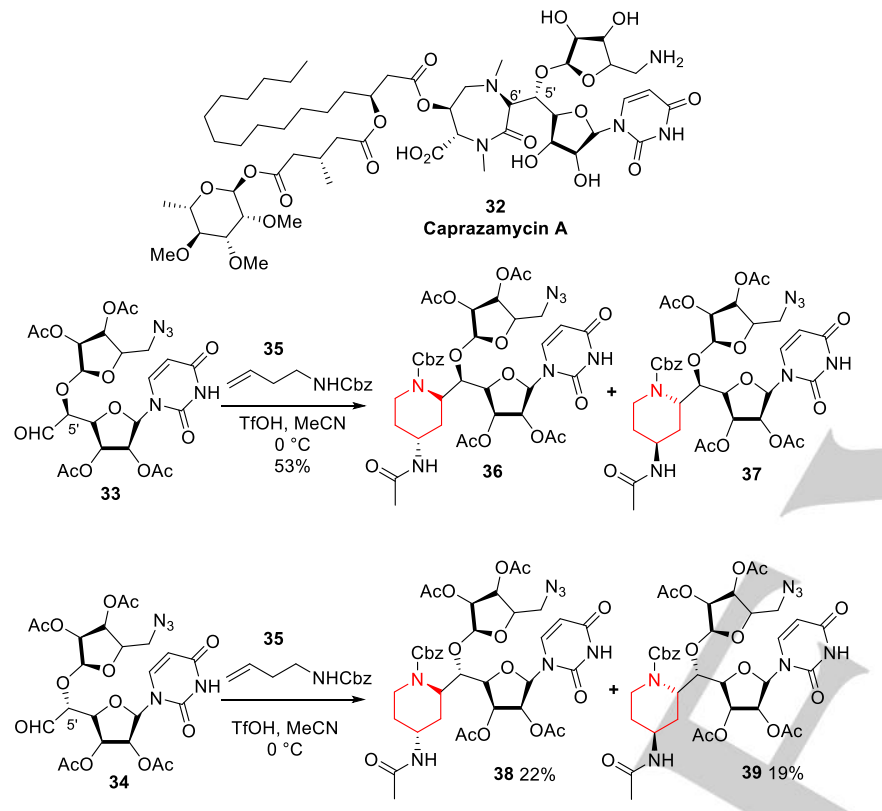

Scheme 8. Aza-Prins-Ritter sequence for the direct synthesis of piperidinylaminoribosyluridines.

Simple manipulations, including deprotection of the acetyl and $\mathrm{Cbz}$ groups and reduction of the azide to amine, delivered compound 40, the other analogues were obtained after grafting the different lipophilic side chains (Scheme 9). Biological tests on phosphof-MurNAc-pentapeptide translocase (MraY) indicated the importance of the stereochemistry at 5'- and 6'-position and the need of a lipophilic side chain. Compounds $43-44-45$ and 46 were found to be more potent inhibitors than 40-41-42 and 47 while the best analogues were identified to be $\mathbf{4 3}$ and $\mathbf{4 6}$.

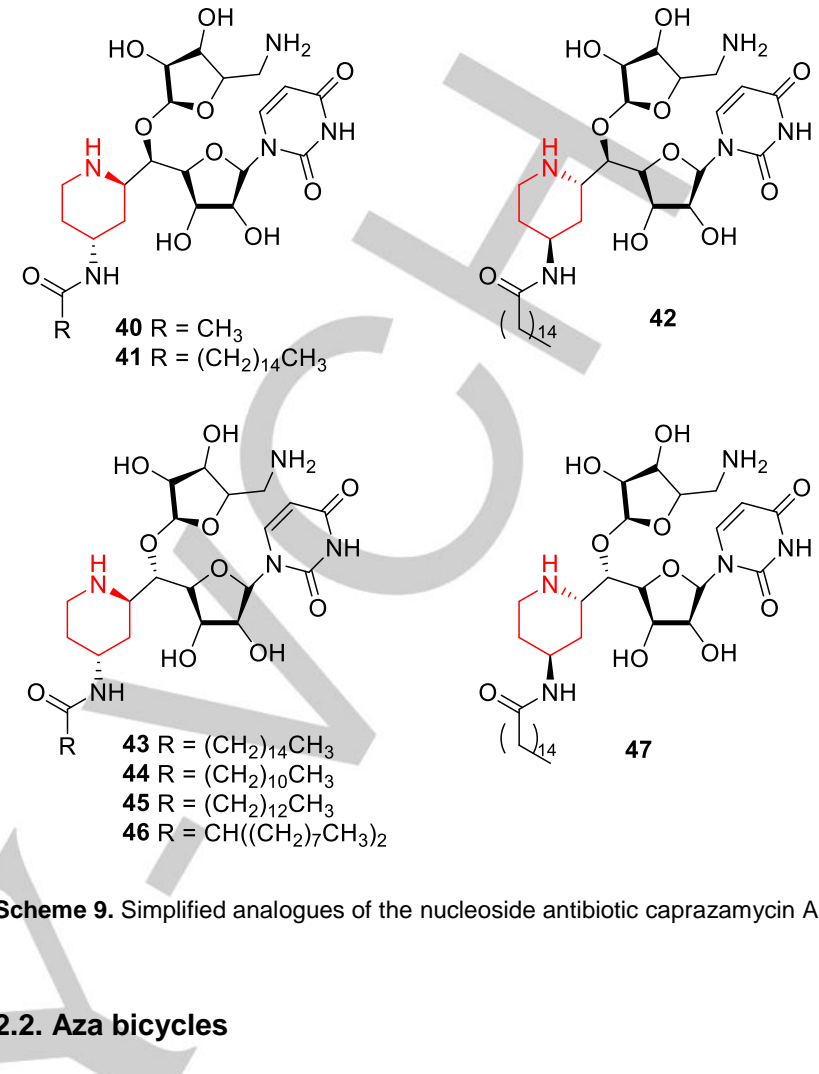

The synthesis of azabicyclic core in concise routes attracts great attention since this motif is found in several biologically active natural products. In particular various alkaloid families with a wide range of activities possess an aza-bicyclic skeleton, for example indolizidine alkaloids such as Castanospermine and Swainsonine that are glycosidase inhibitors and Martinelline which is a bradykinin receptor antagonist, among others. In this section we will describe the methodological efforts made by the community to reach azabicyclic skeletons in one operation step, and then the application to the natural products synthesis.

To achieve the indolizidine core two approaches have been developed, the aza-Prins cyclization from allylpyrrolidines and the intramolecular aza-silyl-Prins cascade that can eventually afford even the quinolizidine skeleton. Waters's group described the synthesis of functionalized indolizidines from 2 allylpyrrolidines $48 .{ }^{9}$ The reaction of the endocyclic amine with formaldehyde or highly activated aldehydes such as glyoxylate derivatives led to the formation of an iminium ion 49 that undergoes nucleophilic attack from the embedded allyl substituent (Scheme 10). Thus the fused bicycle was formed together with two, or eventually three, new stereogenic centers. The reaction proceeded in a complete diastereoselective way, dictated by the equatorial position occupied by the pyrrolidine ring and the axial attack on the resulting carbocation in the transition state. When formaldehyde $\mathbf{5 0}$ was employed, the reaction was conducted in aqueous media thus the nucleophile was water and products $\mathbf{5 1}$ were formed. When glyoxylic acid $\mathbf{5 2}$ was used, the carbocation was trapped by the carboxylic acid and therefore an extra lactone ring $\mathbf{5 3}$ was formed and the substituents were in the 1,3-diaxial position of the piperidine ring. 
Finally when glyoxal $\mathbf{5 4}$ or ethyl glyoxylate $\mathbf{5 5}$ were used indolizidines 56 were formed with 2,4-cis substituents (Scheme 10).

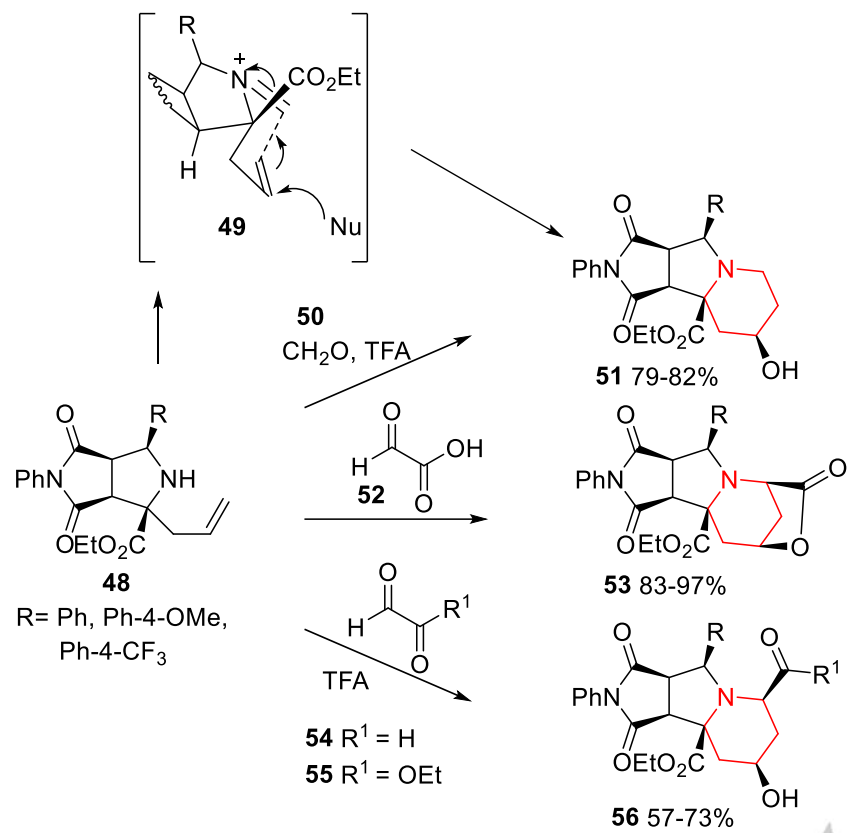

Scheme 10. Indolizidine synthesis from allylpyrrolidines.

In a recent report Dobbs and co-workers presented their studies toward the azabicyclic cores of the indolizidines and quinolizidines. This time both rings were formed in a single intramolecular one-pot cascade initiated by the formation of an acyliminium ion and terminated by an aza-silyl-Prins cyclization. ${ }^{10}$ The amide precursors 57 and $\mathbf{5 8}$ were synthesized to this end, with the aldehyde function masked as acetal. Treatment with the appropriate Lewis acid, $\mathrm{Sc}(\mathrm{OTf})_{3}$ and $\mathrm{FeCl}_{3}$ respectively, delivered the desired indolizidines 59 and quinolizidines 60 in good yields showing that both the aza-silylPrins and the aza-acyliminium-Prins reactions may be combined for the preparation of such azabicycles. (Scheme 11).<smiles>COC(CCC(=O)NCC/C=C\C(C)(C)C)OC</smiles>
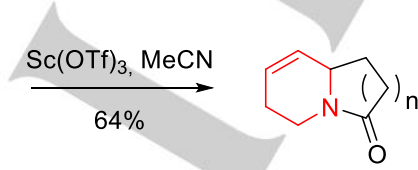

Aza-Silyl-Prins Cyclisation<smiles>C=CCCNC(=O)CCC(CC(OC)OC)OCC</smiles><smiles>O=C1CCC2CC(Cl)CCN12</smiles>

$59 \mathrm{n}=1$ Indolizidine $60 n=2$ Quinolizidine
The synthesis of the octahydro pyrrolo-[3,2-c]pyridine skeleton of Martinelline and Martinellinic acid, molecules that show activities as inhibitor for bradykinin, histaminergic and muscarinic receptors, among others, has been studied by Yadav and Subba Reddy. ${ }^{11}$ The authors proposed an intramolecular aza-Prins cyclization between styrene epoxides 62, as pheny acetaldehyde equivalents, and homoallylic amines containing a tethered amine nucleophile $\mathbf{6 1}$, catalyzed by $p$-TSA at $10 \mathrm{~mol} \%$ (Scheme 12). The reaction proceeded smoothly with the $E$ alkene to give the trans-fused azabicycles $\mathbf{6 3}$ while cis selectivity was observed with the $Z$ olefin, thus the origin of the selectivity comes from the double bond geometry in bistosylamides 61 .
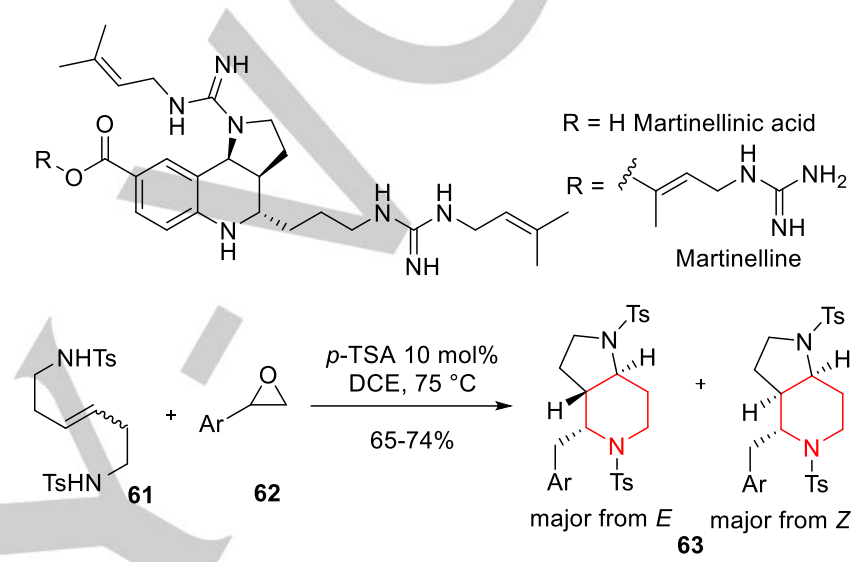

$$
\left[\begin{array}{c}
\text { trans-fused } \\
\text { alkene }
\end{array}\right]
$$

Scheme 12. Synthesis of the octahydro pyrrolo-[3,2-c]-pyridine skeleton of Martinelline and Martinellinic acid via aza-Prins cyclization with epoxides.

The Krasavin's group reported a concise route to aza-bi- and tricycles, found in the skeleton of various natural products including Lycopodium alkaloids, by condensation of amine 64 with aromatic aldehydes or ethyl glyoxylate, in the presence of $\mathrm{BF}_{3}$. $\mathrm{Et}_{2} \mathrm{O}$ and under MW irradiations. ${ }^{12}$ Playing on the amount of aldehyde employed, namely 1 or 2 equivalents, the aza-Prins cyclization led to the formation of 3-azabicyclo[3.3.1]non-6-enes 65 or 1-azatricyclo[3.3.1.1]decanes 66 via a second aza-Prins. Compound 65 was obtained as single endo-diastereomer and as single double bond regioisomer. This regioselectivity was explained by the nitrogen assisted intramolecular deprotonation (Scheme 13). Unsymmetrical substituted 1-azaadamantanes could also be obtained by this methodology through a sequential double aza-Prins cyclization with two different aldehydes. 


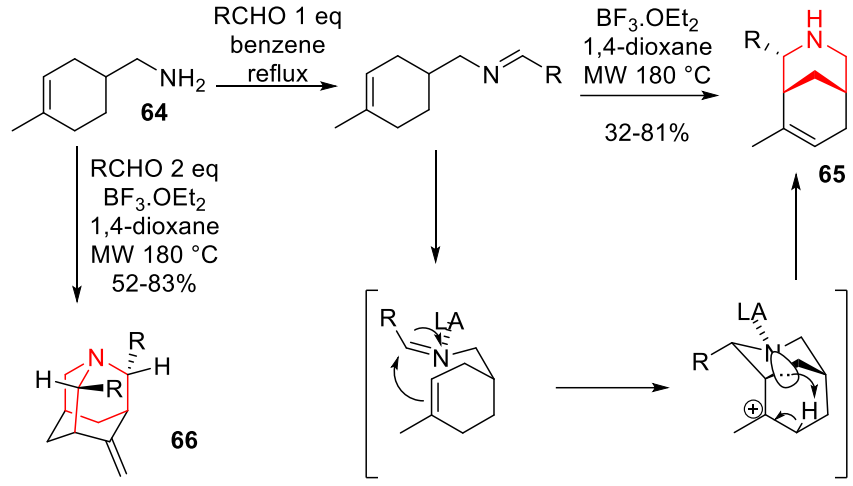

Scheme 13. Synthesis of azabicyclononene and azaadamantane skeletons of biological interest.

Very recently Reisman and co-workers succeeded in the enantioselective synthesis of complex functionalized indolines in a one operational step starting from indoles, through a conjugate addition/asymmetric protonation/aza-Prins cascade. ${ }^{13}$ Indoles with an embedded homoallyl on the 1 or 3 positions, compounds 67 and 68 respectively, undergo smoothly conjugate addition to amidoacrylate, followed by an enantioselective protonation catalyzed by a chiral $\mathrm{ZrCl}_{4}-\mathrm{BINOL}$ complex and in the presence of 2,6-dibromophenol and TMSCl as $\mathrm{HCl}$ source (Scheme 14). The chloride anion played the role of nucleophile source, thus it trapped the carbocation formed after the aza-Prins cyclization and allowed the catalyst turnover. The indolines products were obtained in high yields, high enantioselectivity thanks to the chiral Lewis acid-assisted Brønsted acid, and good diastereoselectivity during the aza-Prins cyclization dictated by the nucleophilic attack of the chloride. Indeed this occurred on the equatorial position for products 69 and on the axial for compounds 70 .

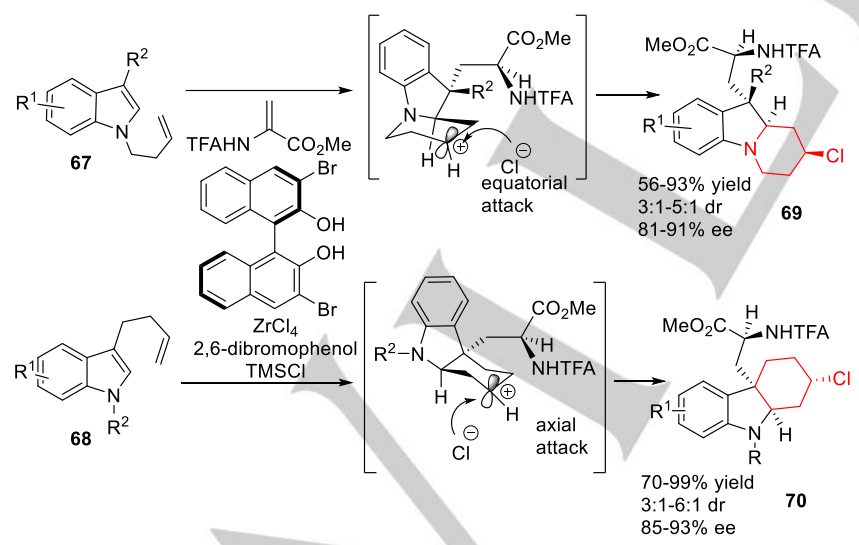

Scheme 14. Enantioselective Lewis acid-assisted Brønsted acid synthesis of functionalized indolines.

Armstrong's group detailed a concise synthesis of the bicyclic alkaloid ( \pm )-Epibatidine $\mathbf{7 6}$ and its analogue $( \pm)$-Epiboxidine $\mathbf{7 4}$
(Scheme 16), poisons extracted from the skin of frogs, and using 7-azabicyclo[2.2.1] heptane 72 as a key intermediate. ${ }^{14}$ This latter was obtained from substituted pyrrolidine $\mathbf{7 1}$ in the presence of equimolar amount of $\mathrm{SnCl}_{4}{ }^{15}$ The authors observed the formation of only the exo $\mathbf{7 2}$ product with respect to the aldehyde function, and this diastereoselectivity could be explained by an unusual aza-Prins-pinacol sequence (Scheme 15).

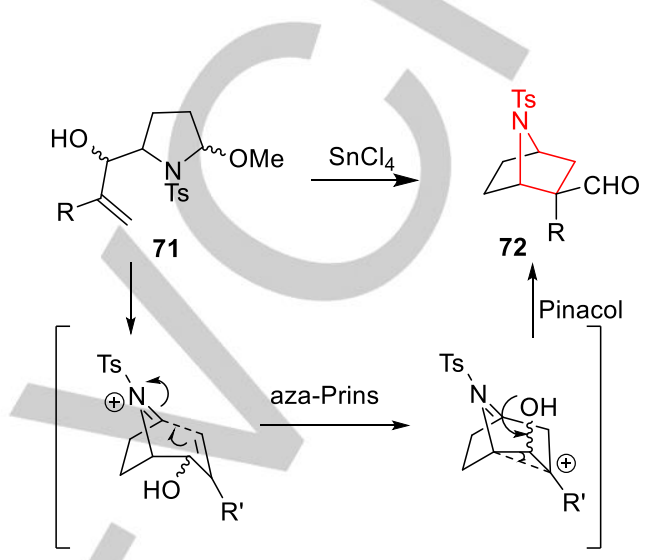

Scheme 15. Aza-Prins-pinacol sequence for the synthesis of the key intermediate towards $( \pm$ )-Epibatidine and $( \pm)$-Epiboxidine.

The aldehyde function on the 7-azabicyclo[2.2.1]heptane skeleton $\mathbf{7 2}$ was exploited by the authors and further converted into the corresponding carboxylic acid 73 by Jones oxidation, in $92 \%$ yield. This intermediate was the entry to $( \pm$ )-Epiboxidine $\mathbf{7 4}$, in $19 \%$ yield over four steps including the formation of the isoxazole ring by cyclization of a $\beta$-ketoxime intermediate. Moreover compound $\mathbf{7 3}$ was transformed in bromide $\mathbf{7 5}$ via Barton bromodecarboxylation, and engaged in a $\mathrm{Ni}(\mathrm{COD})_{2}$ mediated cross coupling reaction with the appropriate pyridine derivative to yield the desired $( \pm)$-Epibatidine $\mathbf{7 6}$ in four steps and $33 \%$ overall yield from 75 (Scheme 16).

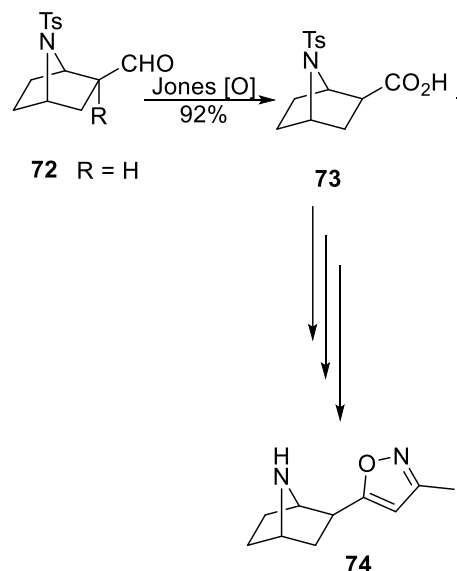

(士)-Epiboxidine

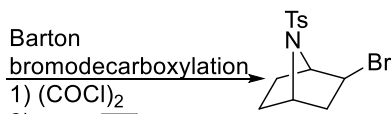

2)

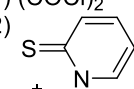
$\mathrm{NaO}^{+}$ 3) $\mathrm{BrCCl}_{3}$ $61 \%$ over 3 steps

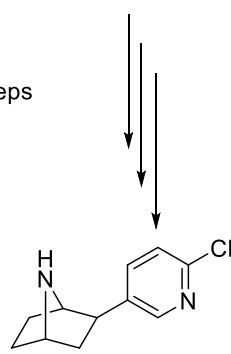

(士)-Epibatidine
Scheme 16. Synthesis of $( \pm)$-Epibatidine and $( \pm)$-Epiboxidine from the common intermediate 72 
Cho and Min envisioned to achieve the total synthesis of the alkaloid Tetrabenazine $\mathbf{8 0}$ and its metabolite Dihydrotetrabenazine $\mathbf{8 1}$, used in the treatment of Huntington's disease, a neurodegenerative disorder, by exploiting an intramolecular aza-Prins-type cyclization of an amino allylsilane through an oxidative $\mathrm{C}-\mathrm{H}$ activation to generate the iminium ion intermediate. ${ }^{16}$ To confirm their strategy an optimization study on a simplified model has been undertaken and among different organic oxidizing agents the combination $\mathrm{DDQ} / \mathrm{LiClO}_{4}$ gave the best results. Thus the authors synthesized the amino allylsilane 77 that underwent smoothly oxidative $\mathrm{C}-\mathrm{H}$ activation/ aza-Prins to give the benzoisoquinolizidine ring system 79 as shown in Scheme 17. The relative configuration of the 2 and 5 carbon atoms on the piperidine ring was assigned to be trans, indicating that in the chair-like transition state $\mathbf{7 8}$ the hindered isobutyl residue occupied the equatorial position while the proton of the imine was in the axial position. The synthesis was completed by oxidative cleavage of the terminal alkene to give the corresponding ketone, thus Tetrabenazine $\mathbf{8 0}$ was obtained from 77 in 2 steps and $33 \%$ yield. Dihydrotetrabenazine 81 was easily synthesized in $80 \%$ yield by further reduction with $\mathrm{NaBH}_{4}$.

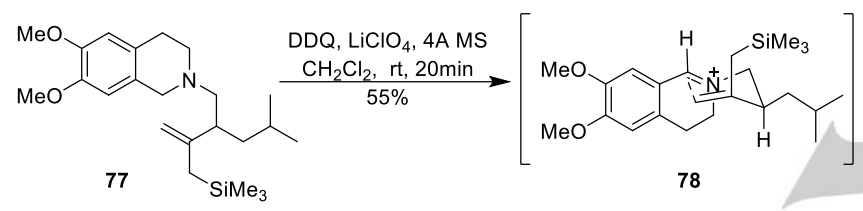<smiles>C=C1CC23CCN(CCc4cc(OC)c(OC)cc42)CC1CC(C)C[N+]3([O-])O</smiles><smiles>COc1cc2c(cc1OC)C1(CCCC1)N(C)CC(CC(C)C)C(=O)C2</smiles><smiles>COc1cc2c(cc1OC)[C@@]13C[C@H](O)C(CC(C)C)CN1CC[C@H]23</smiles>

Scheme 17. Intramolecular aza-Prins-type cyclization/oxidative $\mathrm{C}-\mathrm{H}$ activation for the synthesis of Tetrabenazine and its metabolite.

She and co-workers reported the asymmetric syntheses of two alkaloids clinically used in the place of morphine, as narcotic analgesics with reduced effects of addiction, namely (-)Pentazocine 91 and (-)-Eptazocine 96 (Scheme 19 and 20), via a common strategy involving an aza-Prins cyclization/intramolecular Friedel-Crafts domino reaction as the key step. ${ }^{17}$ This cascade was first validated on a racemic model substrate 82 with formaldehyde (Scheme 18). In the presence of camphorsulfonic acid (CSA) as promoter the desired piperidine 83 was obtained in $95 \%$ yield as a mixture of regioisomers, while with other Lewis or Brønsted acids complex mixtures of products were obtained. The Friedel-Crafts reaction proceeded well in the presence of $\mathrm{AlCl}_{3}$ or $\mathrm{CF}_{3} \mathrm{SO}_{3} \mathrm{H}$ to give the bicycle 84 .

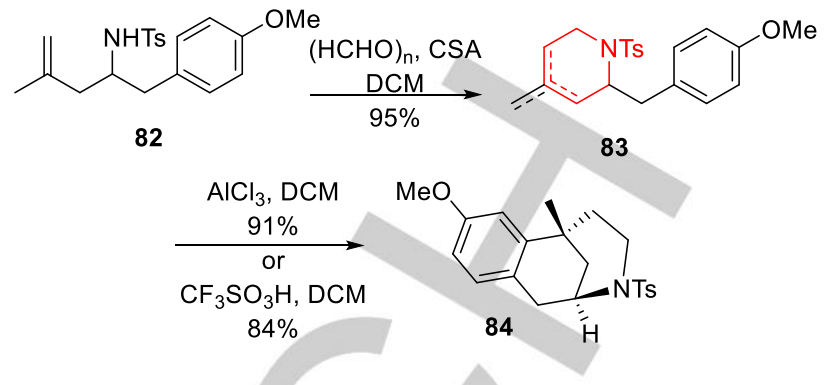

Scheme 18. Aza-Prins cyclization/intramolecular Friedel-Crafts domino reaction en route to (-)-Pentazocine and (-)-Eptazocine skeleton.

The formal total synthesis of (-)-Pentazocine started with the preparation of intermediate $\mathbf{8 7}$, obtained in $28 \%$ yield over 9 steps from aldehyde $\mathbf{8 5}$ and the chiral auxiliary $\mathbf{8 6}$, as shown in Scheme 19. By applying the best reaction conditions for the aza-Prins/Friedel-Crafts reaction, compound 87 delivered the desired piperidine 88 and then the benzobicyclo[3.3.1] 89 in good yields and as a mixture of diastereomers at the C-9 position in a ratio $\alpha: \beta=3: 1$. After deprotection and prenylation of the $N$ atom, the two diastereomers were separated at this stage to keep only the $\beta$-Me $\mathbf{9 0}$. The synthesis of (-)-Pentazocine 91 could be completed, after a final demethylation step, as described by Trost $^{18}$ (Scheme 19).

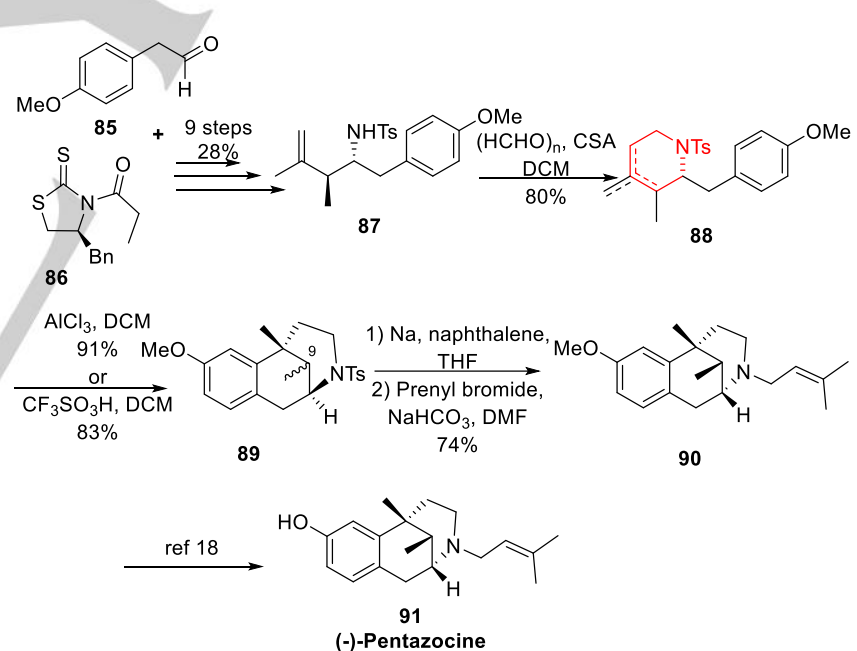

Scheme 19. She's formal total synthesis of (-)-Pentazocine.

Towards Eptazocine, the enantiopure intermediate 94 was synthesized from 92 and 93 in 5 steps and $60 \%$ overall yield, again using a thiazolidinethione as chiral auxiliary. The key intermediate 94 was submitted to the tandem aza-Prins/FriedelCrafts this time by treatment with $\mathrm{CF}_{3} \mathrm{SO}_{3} \mathrm{H}$ and then $\mathrm{AlCl}_{3}$ to give bicycle 95 in $80 \%$ yield on the overall domino reaction. A final protection/deprotection sequence furnished (-)-Eptazocine 96 in 3 steps and 57\% yield from 95 (Scheme 20) 


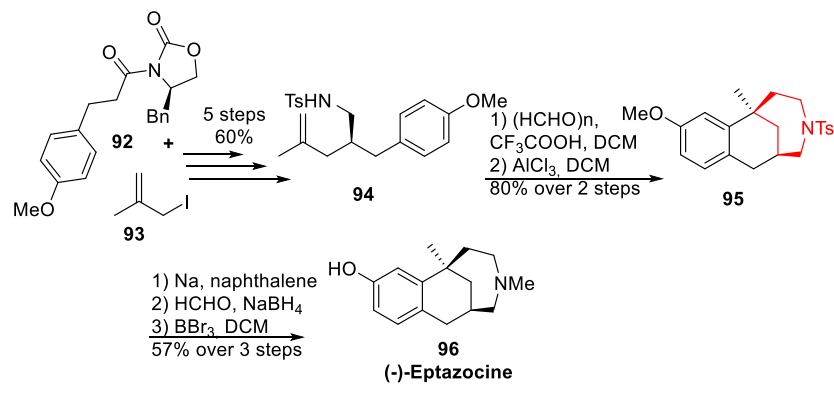

Scheme 20. Total synthesis of (-)-Eptazocine.

Very recently Maison's group has reported a domino azaPrins/Friedel-Crafts reaction for the synthesis of a library of benzomorphanes, including the skeleton of (-)-Pentazocine 91 ref This represent actually the shortest formal synthesis of this opioid analgesic, obtained in only 6 steps starting from the commercially available 3-buten-2-one 97, while the previous described synthesis by She was accomplished in 13 steps. The author's prepared the homoallylic amine 98 in 2 steps and $58 \%$ yield, including the formation of the $\alpha$-aminoketone and a Wittig olefination (Scheme 21). The aza-Prins/Friedel-Crafts domino reaction was performed in the presence of aldehyde 85 and in a one-pot fashion, by treatment with $10 \mathrm{~mol} \%$ of TMSOTf, followed by addition of 1.2 eq. of $\mathrm{CF}_{3} \mathrm{SO}_{3} \mathrm{H}$. The desired adduct 99 was obtained in $49 \%$ yield in a ratio $\alpha: \beta=4.3: 1$, and it can be converted according to reported procedures, ${ }^{17,18}$ into the desired $(-)$-Pentazocine.

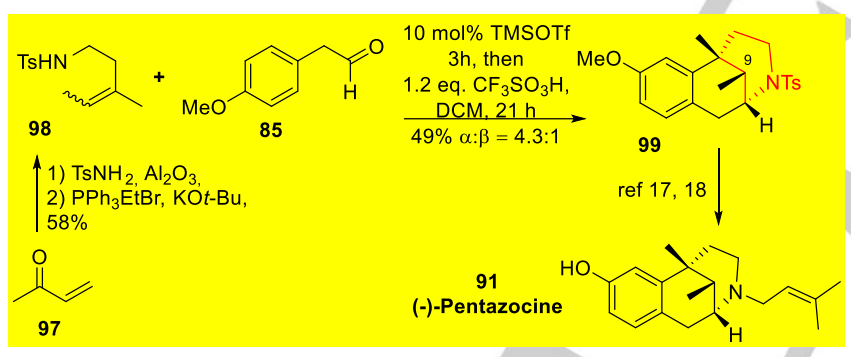

Scheme 21. Maison's formal total synthesis of (-)-Pentazocine.

Hanessian's group has developed an intramolecular $N$ acyliminium carbocyclization with different embedded carbon nucleophiles, such as alkene, alkynes and even allenes in order to get aza bi- and tricyclic scaffolds. ${ }^{19}$ This methodology has been applied as key step in the first total synthesis and structural confirmation of the antithrombotic marine natural product Oscillarin 102, also called D-Pla-D-Phe-L-Choi-Adc. ${ }^{20}$ The synthesis started from $\mathrm{N}$-Boc-L-glutamate 97 which has been transformed into the hemiaminal 98 in five steps and 64\% overall yield. Treatment of $\mathbf{9 8}$ with $\mathrm{SnBr}_{4}$ afforded the desired octahydroindole 101 in $78 \%$ yield through the formation of the $\mathrm{N}$ acyliminium ion 99 and intramolecular trapping by the tethered alkene (Scheme 21). The stereochemical control can be explained by a chair like transition state 99 in which the $\omega$ - olefinic nucleophilic carbon and the iminium ion are antiperiplanar, in order to minimize the allylic strain, and the bromide attacks the incipient carbocation 100 from the equatorial position. To complete the synthesis, the Dphenyllactyl-D-phenylalanine and the pyrrolino-guanidine chains needed to be installed on the L-Choi unit. Thus oscillarin 102 was obtained in 8 steps from the key 1-aza[4.3.0]-bicycle core 101 in $34 \%$ overall yield (Scheme 21 )

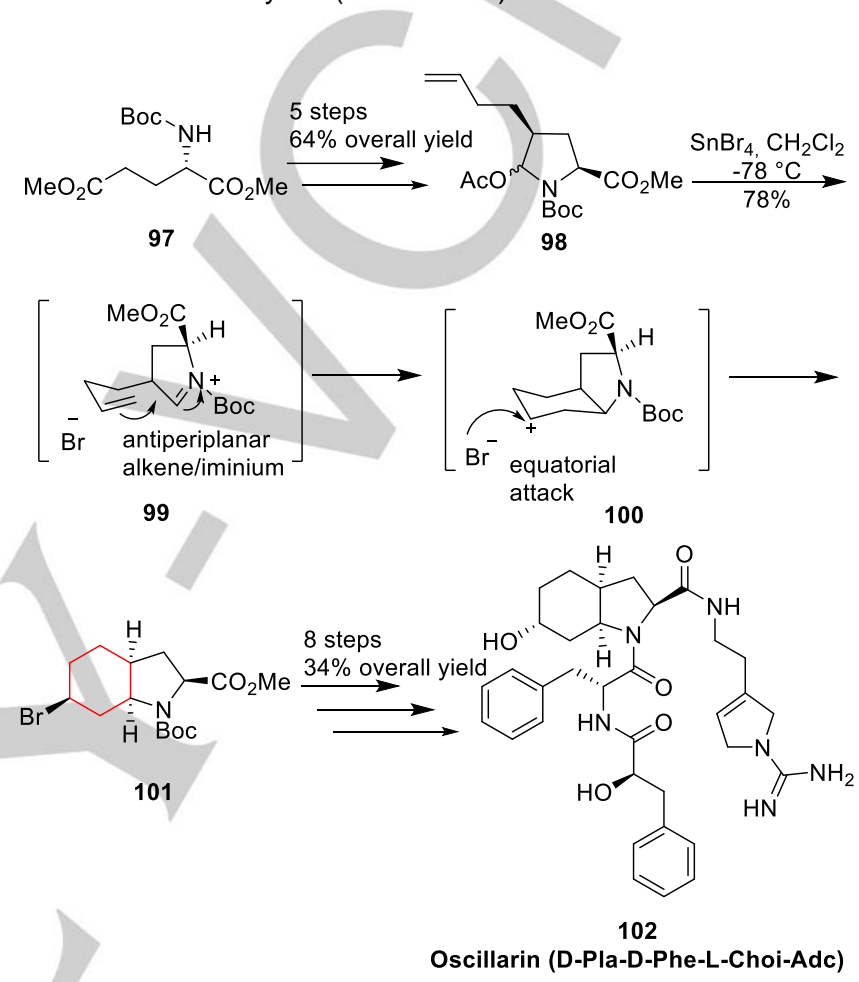

Scheme 21. Synthesis of Oscillarin via $\mathrm{N}$-acyliminium carbocyclization.

Saikia and co-workers established a very efficient protocol for the synthesis of azabicyclic hexahydroindolizinones and hexahydroquinolizinones via a tandem aza-Prins/Friedel-Crafts or aza-Prins/Ritter sequences of cyclic $\mathrm{N}$-acyliminium ions mediated by $\mathrm{BF}_{3} . \mathrm{Et}_{2} \mathrm{O} .{ }^{21}$ The extension of this methodology to the use of $p$-toluenesulphonic acid as promoter led to the synthesis of $O$-tosyl hexahydroquinolizinones were $p$-TSA acts as Brønsted acid and nucleophile. This method was successfully applied to the total synthesis of $( \pm)$-epi-Indolizidine 167B and 209D, member of a class of alkyl indolizidine alkaloids, known to be blockers of neuromuscular transmission. ${ }^{22}$ The authors synthesized in two steps starting from succinimide 103, the carbinols 104 and 105 in 63\% and 65\% yield respectively. Those later underwent aza-Prins cyclization and trapping with tosylate to deliver the tosylated azabicyclic products 108 and 109 in $79 \%$ and $84 \%$ respectively, as single isomers (Scheme 22). The stereocontrol was due to the more favored transition state $\mathbf{1 0 6}$ in which the alkyl $R$ chain was axial in order to minimize the angular strain with the $\mathrm{C}=\mathrm{O}$ group of the lactam ring, followed by equatorial attack of the tosylate nucleophile on the carbocation 107. The target alkaloids ( \pm )-epi-Indolizidine 167B 110 and 209D 
111 were finally obtained after removal of the OTs group in the presence of $\mathrm{NaBH}_{4}$ and reduction of the lactam with $\mathrm{LiAlH}_{4}$, in $56 \%$ and $62 \%$ yield respectively over 2 steps.

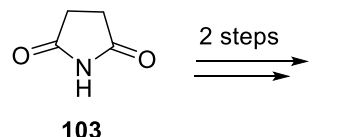

103<smiles>[R]C(CC=C)N1C(=O)CC[C@H]1O</smiles>

$104 \mathrm{R}=n$-propyl $63 \%$ $105 \mathrm{R}=n$-hexyl $65 \%$

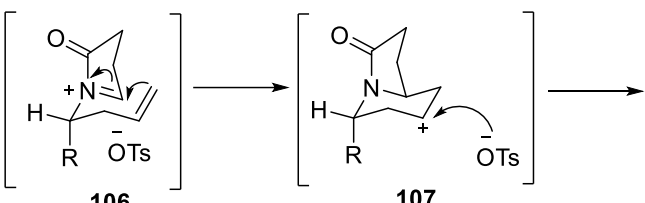

106<smiles>CC(C)[C@H]1CCC[C@@H]2CCCN21</smiles>
rac-epi-Indolizidine 167B $56 \%$

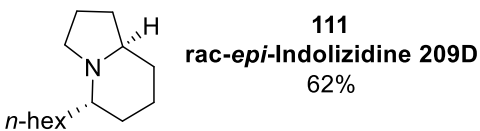

$$
n \text {-hex" }
$$$$
62 \%
$$

$108 \mathrm{R}=n$-propyl $79 \%$ $109 \mathrm{R}=n$-hexyl $84 \%$

Scheme 22. Synthesis of alkaloids (士)-epi-Indolizidine 167B and 209D via aza-Prins cyclization and trapping with tosylate anion.

\subsection{Complex polycyclic heterocycles}

This section is devoted to the synthesis of complex skeletons of natural products, in particular Lycopodium alkaloids which possess a tetracyclic core and have been used for long time in traditional Chinese medicine and homeopathic therapies. In this part we will discuss the synthesis of Huperzine A, Nankakurines, Lycopodines, Lycospidine A and Lyconadines, belonging to this alkaloid family; then the synthesis of Cilindricines, Crepidines analogues and Cortistatin A will be detailed.

White's group reported the formal total synthesis of the alkaloid (-)-Huperzine A 119, an acetylcholinesterase inhibitor, exploiting as key step a tandem sequence including an intramolecular azaPrins cyclization followed by a cyclobutane fragmentation for the construction of the bicyclo[3.3.1]nonene core of the natural product. ${ }^{23}$ To introduce the chirality the authors exploited the chiral pool, thus the route began with D-(-)-quinic acid 112 (Scheme 23). The strategy to get the key intermediate 115 reposed on three milestones including $[2+2]$ intramolecular photocycloaddition to achieve bicyclo[4.2.0]octanone 113, [2+2] pyridine annulation for the construction of 114 and finally reductive cleavage of the tetrahydrofuran to get the cyclobutane ring of 115. With this key intermediate in hands the authors attempted the cascade reaction: condensation of the ketone moiety with methyl carbamate furnished in situ the imino ester 116, prone to undergo intramolecular aza-Prins cyclization promoted by anhydrous $\mathrm{TsOH}$. Finally the resulting cyclobutylcarbinyl cation 117 was subjected to fragmentation of the a bond to give the known compound $\mathbf{1 1 8}$ in $37 \%$ over the cascade process (Scheme 23). The synthesis could be completed, as reported by Kozikowski, by treatment with TMSI in chloroform. ${ }^{24}$

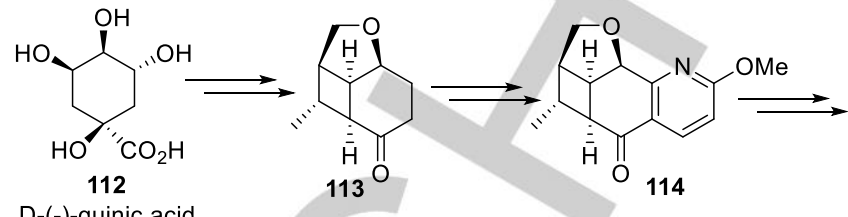

D-(-)-quinic acid

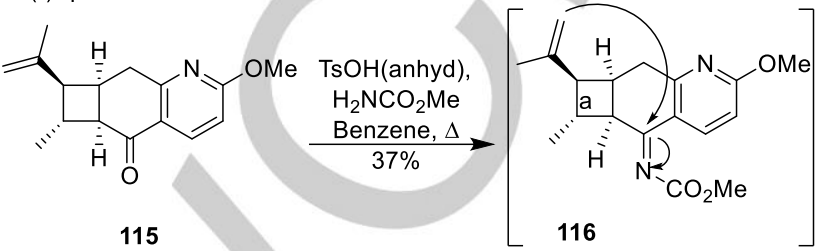

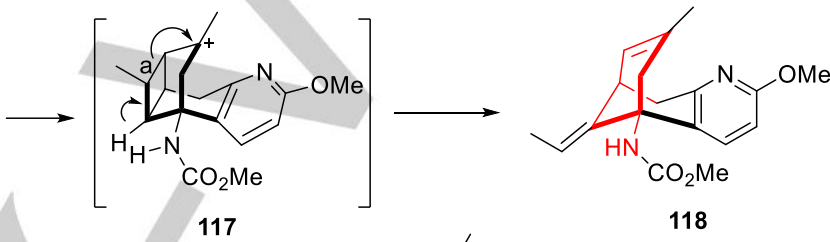
117

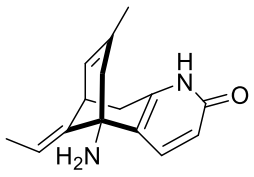

119

(-)-Huperzine A

Scheme 23. Intramolecular aza-Prins cyclization/cyclobutane fragmentation for the synthesis of (-)-Huperzine A.

Overman and co-workers attempted the total synthesis of Nanakakurine A. Kobayashi's group proposed, in 2004123 for the structure and relative stereochemistry of the spiranic stereocenter of the isolated molecule, ${ }^{25}$ but two years later they revised the original structure into compound 124 (Scheme 24). ${ }^{26}$ In order to elucidate the structure and absolute configuration of Nanakakurine and because of the scarce availability of this alkaloid and its congeners potentially useful in the treatment of neurodegenerative disorders such as Alzheimer's and Parkinson's disease, the authors have undertaken the synthesis of these alkaloids. The proposed synthetic plan was based on an unprecedented amino-terminated aza-Prins cyclization to construct the tetracyclic core of the natural product. ${ }^{27}$ For this goal, the authors synthesized the cis-fused decalin amine 120 that was readily converted into the corresponding carbamate 121 in $80 \%$ yield. Reaction of this carbamate with one equivalent of paraformaldehyde in the presence of TFA furnished a tetracyclic product intermediate 122 through a sulfonamideterminated aza-Prins cyclization, albeit in low yield (10-20\%), together with a complex mixture of other cyclic products. At this stage all efforts to increase the yield of the aza-Prins cyclization failed, thus the author terminated the synthesis after removal of the tosyl group with $\mathrm{Na} / \mathrm{NH}_{3}(98 \%$ yield) and reduction of the carbamate by treatment with $\mathrm{LiAlH}_{4}(65 \%$ yield). They obtained a product 123 corresponding to the first proposed structure, 
namely ( \pm )-5-epi-Nankakurine A (Scheme 24). Therefore this synthetic work allowed to unambiguously establishing the structure of the natural product. Finally, Nankakurine A 124 was synthesized via another route, involving an intramolecular [3+2] cycloaddition.

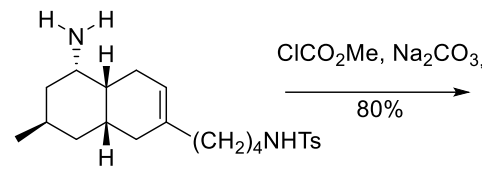

120

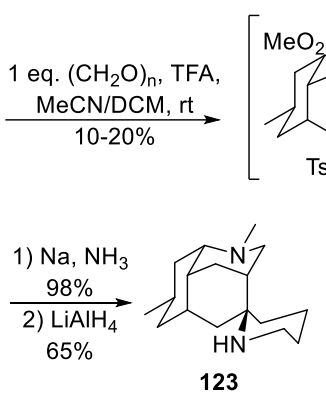

(士)-5-epi-Nankakurine $\mathrm{A}$

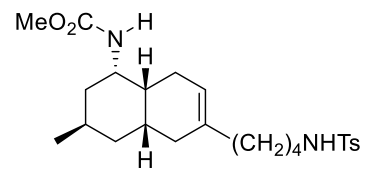

121

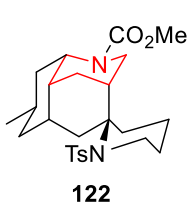

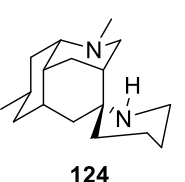

(+)-Nankakurine A
Scheme 24. Sulfonamide-terminated aza-Prins cyclization towards the synthesis of $( \pm)$-5-epi-Nankakurine A.

The $N$-benzyl cis-fused decalin amine 125 was the key intermediate also in the Fukuyama's syntheses of the tetracyclic skeleton of Lyconadins A-C 130-132.28 These molecules exhibit various activities including, among others, cytotoxicity against carcinoma cells in rats and enhanced mRNA expression for nerve growth factor. In this case, treatment of 125 with formaldehyde in acetic acid and in the presence of $\mathrm{SiO}_{2}$ gave the desired aza-Prins tricycle 126 in $81 \%$ yield (Scheme 25). After a deprotection/protection sequence, the dibromocyclopropanation gave, in $61 \%$ overall yield, the compound 127 which is the common intermediate for the synthesis of the three congeners of lyconadins. Indeed electrocyclic ring opening upon cleavage of the dibromocyclopropane and deprotection of the Boc group, afforded 128 that was further manipulated to complete the synthesis of Lyconadin C $\mathbf{1 3 0}$. When the ring expansion was accompanied by the formation of a $\mathrm{C}-\mathrm{N}$ bond, then the tetracyclic compound $\mathbf{1 2 9}$ was obtained and this could be finally transformed into the desired Lyconadin A 131 and B 132.

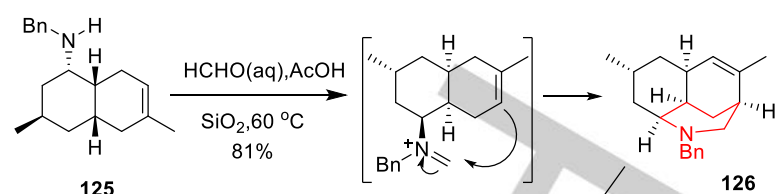

125

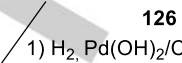
2) $\mathrm{Boc}_{2} \mathrm{O}$ 3) $\mathrm{CHBr}_{3}, \mathrm{BnNEt}_{3} \mathrm{Cl}$
$61 \%$
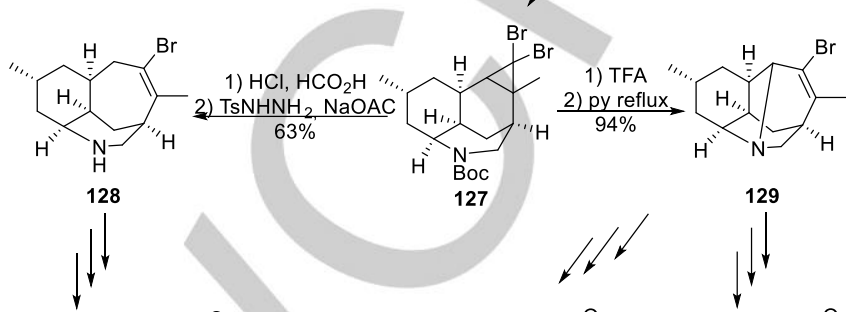

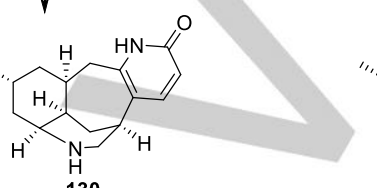

130

Lyconadin C

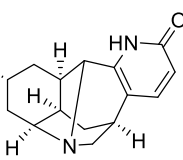

131

Lyconadin A

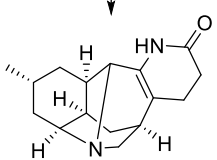

132 Lyconadin B
Scheme 25. Synthesis of the tricyclic skeleton of Lyconadins A-B-C via an aza-Prins cyclization.

Very recently She's group succeeded in the asymmetric total synthesis of two Lycopodium alkaloids, having a tetracyclic core, (-)-Lycopodine 140 and (-)-Lycospidine 141, which have been used in Chinese folk medicine as analgesic for example. ${ }^{29}$ The main difference between the core structure of the two natural products resides in the $A$ ring, where for (-)-Lycopodine it is a 6 membered-, while for (-)-Lycospidine it is a 5 membered-ring (Scheme 26). The authors designed a synthesis for both alkaloids starting from the commercially available $(R)$-pulegone as chiral source, and as $D$ ring. They easily obtained the intermediate $\mathbf{1 3 3}$ that was transformed into the bicyclic alkyneamide 134, through amidation reaction followed by cyclization. In this way the $C$ ring was formed. The intramolecular alkyne azaPrins cyclization proceeded in the presence of formic acid and $85 \%$ phosphoric acid via the formation of the $\mathrm{N}$-acyliminium ion 135 that undergoes cyclization to give 136 and then tautomerization of the enol to give the BCD tricyclic skeleton 137 in $99 \%$ yield. The same intermediate can be obtained in a onepot procedure starting from $\mathbf{1 3 3}$ and allylamine, in the presence of acetic acid and $85 \%$ phosphoric acid in $90 \%$ yield. Thus in a single operation consisting in the amidation/cyclization/alkyne aza-Prins, three bonds and the $\mathrm{C}$ and $\mathrm{B}$ rings were formed, together with two contiguous stereogenic centers, including a quaternary one (Scheme 26). This key intermediate 137 was the starting point for the last cyclization, achieved by aldo condensations, leading on one hand to the tetracyclic 138 , containing a newly formed piperidine ring, and on the other hand to the unique five membered $A$ ring of 139 . To complete the synthesis of (-)-Lycopodine 140, reduction of both the lactam to amine and the ketone to alcohol, followed by re-oxidation of the alcohol were necessary. (-)-Lycospidine $\mathbf{1 4 1}$ was obtained after 
a late stage oxidation on the $\mathrm{B}$ ring, followed by a reduction/reoxidation sequence.

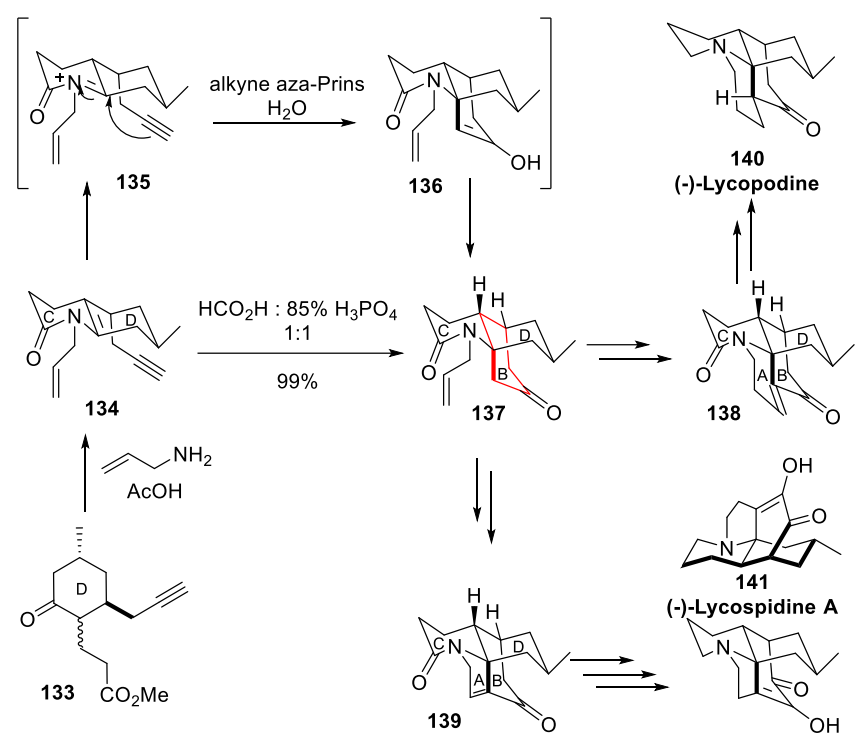

Scheme 26. Acyliminium alkyne aza Prins for the enantioselective synthesis of (-)-Lycopodine and (-)-Lycospidine.

The synthesis of other natural products, beyond that of the Lycopodium alkaloids, has also been attempted via the azaPrins cyclization as key step. Hsung and co-workers successfully carried out the total syntheses of (-)-Lepadiformine 149 and (+)-Cylindricines C-E 150-152 (Scheme 27), ${ }^{30}$ which show moderate cytotoxicity against various tumor cell lines in vitro. These were performed through a common intermediate, the aza tricyclic compond 147, derived from an aza-Prins cyclization and Wharton's rearrangement (Scheme 28). This intermediate was synthesized through a multistep sequence starting from butyrolactam 142 which, on addition of the appropriate lithium derivative, led to the amino ketone 143. This latter was submitted to a formic acid-promoted aza-acyliminiumPrins cyclization to give the aza spirocyclic skeleton 144 as formyl protected allylic alcohol. After in situ deprotection by $\mathrm{K}_{2} \mathrm{CO}_{3}$ in $\mathrm{MeOH}$, the bicyclic derivative 145 was obtained in $64 \%$ yield over 2 steps. Further transformations on this intermediate, including a Warthon's rearrangement to transpose the allylic alcohol, led to the compound 146. Finally treatment with TFA to cleave the Boc group allowed the cyclization to deliver the key tricycle 147 in $72 \%$ yield.
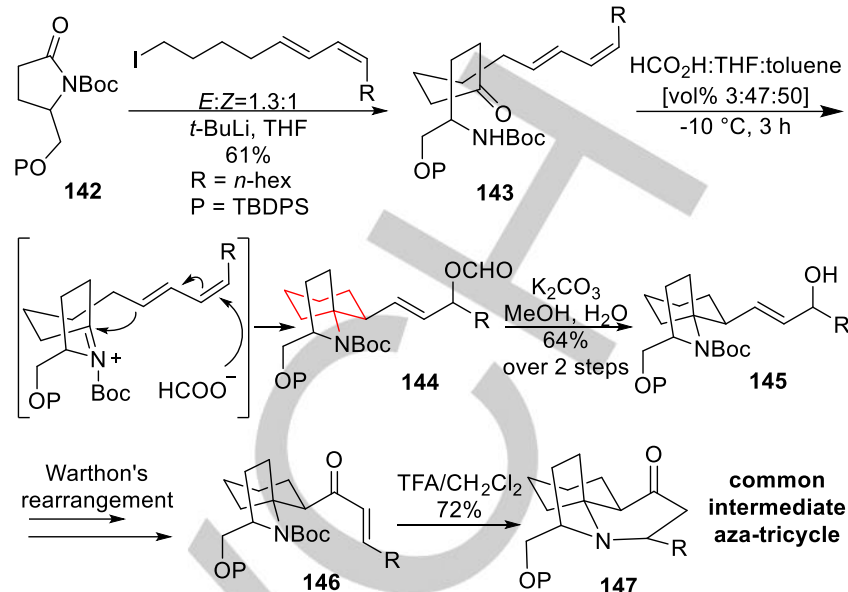

Scheme 27. Synthesis of the common aza-tricyclic intermediate towards (-)Lepadiformine and (+)-Cylindricines C-D-E, via aza-Prins cyclization and Wharton's rearrangement.

The synthesis of (-)-Lepadiformine 149 was completed after deoxygenation of the C-4 carbonyl. This could be achieved after the selective reduction with $\mathrm{NaBH}_{4}$, leading exclusively to the $\beta$ hydroxyl group, then transformation into xanthate 148 (Scheme 28). Deoxygenation and desilylation furnished the desired target molecule 149. To achieve the synthesis of $(+)$-Cylindricines the epimerization at the C-5 level was necessary (Scheme 28). Fortunately, the authors observed spontaneous epimerization of intermediate 147 already on silica gel, thus they optimized this process and by using TBAF they obtained concomitant desilylation, affording (+)-Cylindricine C 150 in 91\% yield. Further manipulations delivered also (+)-Cylindricines D 151 and E 152.

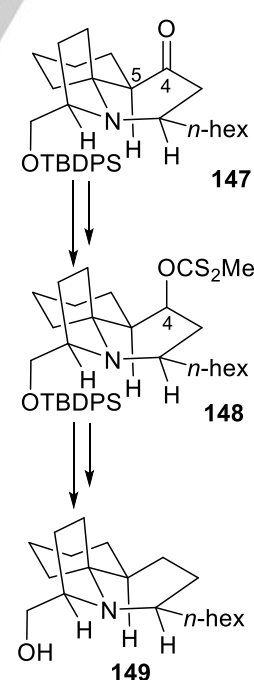

(-)-Lepadiformine
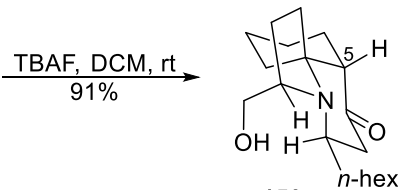

150

(+)-Cylindricine C

$$
\begin{gathered}
\mathrm{Mel}, \mathrm{Ag}_{2} \mathrm{O} \\
\text { or } \\
\text { DMAP, } \mathrm{AcCl}
\end{gathered}
$$

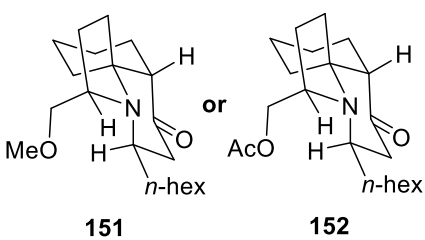

(+)-Cylindricine D (+)-Cylindricine E $45 \%$ 
Another approach to those natural products involved a tandem Mannich strategy. Kibayashi was the first to succeed in the synthesis of (-)-Lepadiformine $\mathbf{1 4 9}$ thanks to an $\mathrm{N}$-acyliminium intramolecular spirocyclization of compound 154 directly synthesized from (S)-153 with the appropriate Grignard reagent. ${ }^{31}$ Treatment of $\mathbf{1 5 4}$ with formic acid gave in $88 \%$ yield the spiranic bicyclic intermediate $\mathbf{1 5 6}$ with a good regiocontrol, dictated by the stability of the chairlike transition state 155 (Scheme 29). Further transformations including the hydrolysis of the formate, the oxidation and diastereoselective reduction, and finally the cyclization to give the tricyclic amine, were necessary to obtain the target natural product.

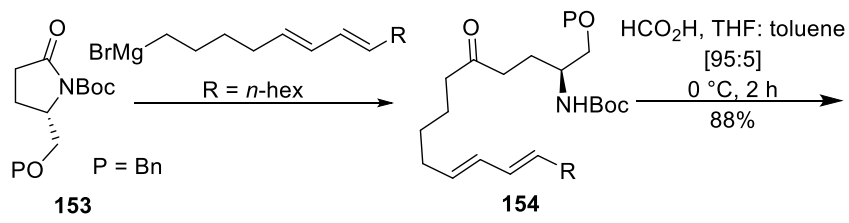

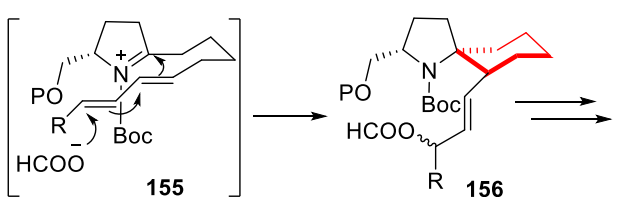

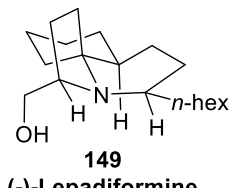

Scheme 29. Mannich strategy for the synthesis of (-)-Lepadiformine $\mathrm{N}$ acyliminium intramolecular spirocyclization.

Shair's group reported an enantioselective synthesis of (+)Cortistatin A 164, a potent and selective inhibitor of endothelial cell proliferation, through an aza-Prins/transannular cyclization as the key sequence to construct the $A$ ring of the natural product (Scheme 30). ${ }^{32}$ The synthesis started from optically pure Hajos-Parrish ketone 157 that was transformed into tricyclic $\beta, \gamma$-unsaturated enone 158 in 8 steps. Further manipulations included a ring expansion to afford compound 159. This latter was the precursor of the aldehyde $\mathbf{1 6 0}$ that was obtained after removal of the TES group and oxidation with Dess-Martin periodinane. This key intermediate was readily engaged in the aza-Prins cyclization with 3 equivalents of dimethylamine in the presence of $\mathrm{ZnBr}_{2}$. The following cascade reactions started with the construction of the A ring via diastereoselective aza-Prins cyclization (Scheme 30). The formation of the C-3 stereocenter was controlled by the boat conformation of the iminium ion 161, thus the $\mathrm{H}$ and the iminium were coplanar to avoid 1,3 allylic strain, while the OAc group blocked the Re face allowing the addition on the $\mathrm{Si}$ face. Simultaneously the transannular cyclization initiated by the ether in the C-8 position occured to afford the oxabicylo[3.2.1]octane 162. The sequence was terminated by the deprotection of MEM protecting group, thus the oxonium ion release delivered directly compound 163 . The synthesis was completed in further five steps including the installation of the isoquinoline group.

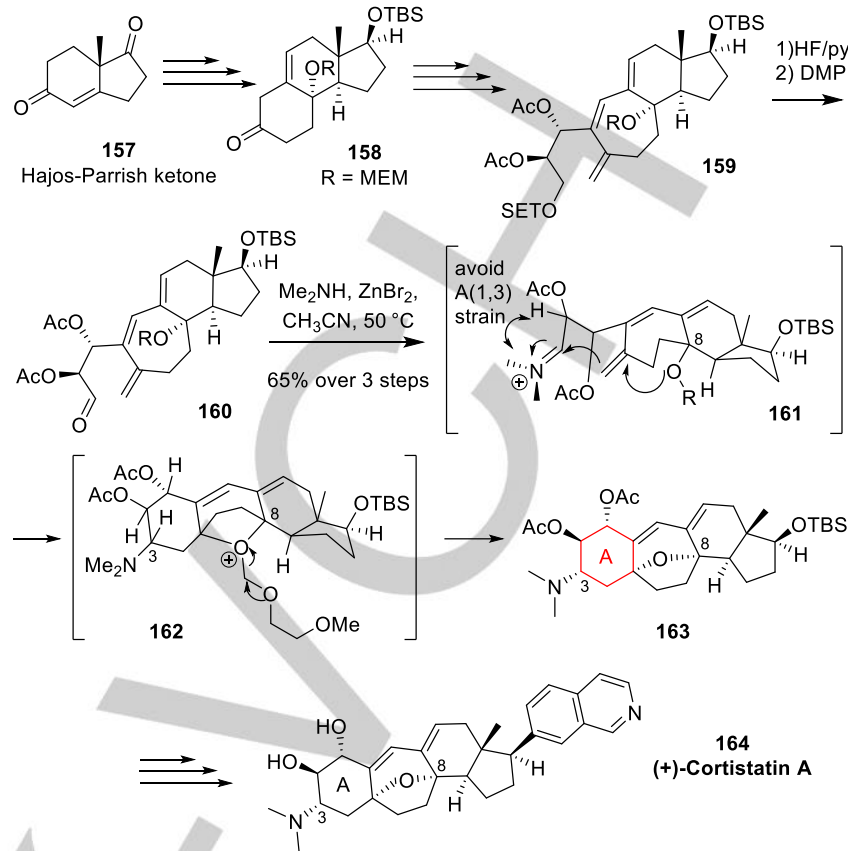

Scheme 30. Synthesis of (+)-Cortistatin A through an aza-Prins/transannula cyclization.

In their efforts towards the synthesis of Alkaloid (-)-205B 165 extracted as traces from the frog skin, Delair and co-workers reported a new stereoselective approach to the $8 \mathrm{~b}$ azaacenaphthylene core via a domino partial reduction/azaPrins cyclization. ${ }^{33}$ The authors prepared lactam 166 that was subjected to vinylogous Mannich to lead to the pyrrolidine 167 (Scheme 31). This latter delivered the indolizinone 168 through lactamization. The strategy aimed to reduce the lactam in order to form an iminium ion that undergoes attack from the double bond. Unfortunately attempts to cleanly get the tricyclic skeleton of Alkaloid (-)-205B failed. Indeed the reduction of 168 with $\mathrm{LiAlH}_{4}$ followed by addition of formic acid and saponification of the formate intermediate, afforded a mixture of diastereomers at the C-4 center together with a product of over reduction, in $62 \%$ yield. The diastereomers were separated and disappointingly the analysis of major product $\mathbf{1 6 9}$ revealed an epimerization at the C-6 stereocenter.

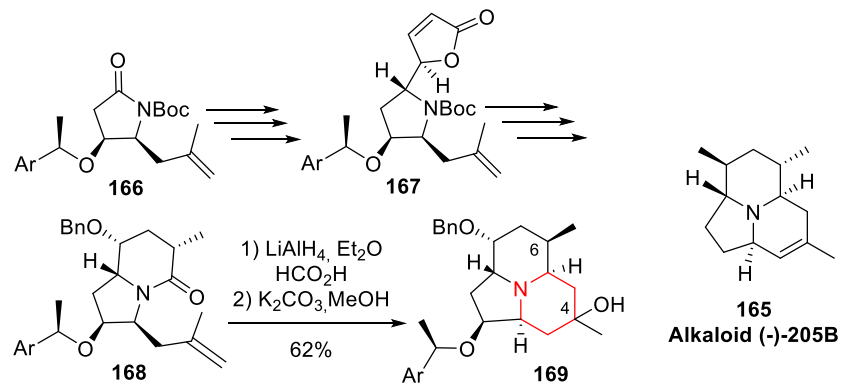

Scheme 31. Domino partial reduction/aza-Prins cyclization approach to the azaacenaphthylene core of Alkaloid (-)-205B. 


\subsection{New aza-Prins-type cyclizations}

In recent years, chemists have developed new strategies, inspired from aza-Prins reaction, in which iminium intermediates are generated by completely different routes. This includes acidmediated cleavage of heterocycles such as aminals, or protonation of various aza-heterocycles, to give iminiums different from those obtained in previous sections. These azaPrins-derived approaches allowed the synthesis of natural products with complex skeletons, as described in the following examples.

This section is devoted to, via strategies that rely on inspired aza-Prins cyclization as key step.

Li's group reported the total synthesis of the drimentine alkaloids A, F and $G \mathbf{x x}-\mathbf{x x}$, which show anticancer, antibacterial as well as antifungal activities. Moreover they reported the bioinspired synthesis of Indotertine A xx, simply by treatment of Drimentine $\mathrm{F} \mathbf{x x}$ with $\mathrm{Bi}(\mathrm{OTf})_{3}$ and in presence of $\mathrm{KPF} 6$, in $78 \%$ yield (Scheme $\mathbf{x x}$ ). ${ }^{34}$ The pathway should go through the formation of the iminium specie $\mathbf{x x}$, followed by iminium-olefin cyclization to give the cationic intermediate $\mathbf{x x}$, which undergoes proton elimination to yield the desired Indotertine A.

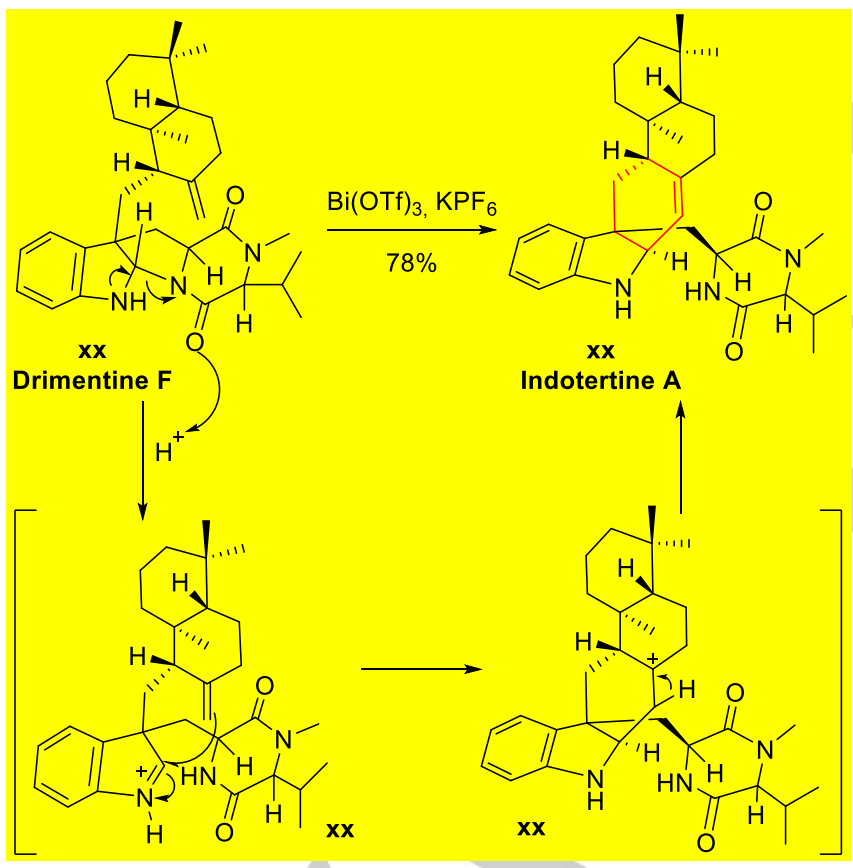

Scheme xx. Bioinspired synthesis of Indotertine A.

The same group reported the bioinspired total synthesis of Sespenine $\mathbf{x x}$, an indolosesquiterpenoid showing a spirotetrahydroquinoline moiety exhibiting antimicrobial activities against several bacteria. The key step of this synthesis includes an aza-Prins/Friedel-Crafts/retro Friedel-Crafts cascade. ${ }^{35}$ The authors synthesized the indosespene-type intermediate $\mathbf{x x}$ with a methoxycarbonyl substituent in the $\mathrm{C}-2$ position and they optimized the reaction conditions for the oxidation on the position C-3. Treatment of $\mathbf{x x}$ with oxone/acetone gave an inseparable mixture of two hydroxyindolenine $\mathbf{g g}$ and $\mathbf{y y}$, epimers on the C-3 (Scheme $\mathbf{x x}$ ). These latter were treated with $\mathrm{AcOH}$ to yield in only $1 \mathrm{~h}$ the desired spirocycle $\mathrm{zz}$ in $58 \%$ yield over 2 steps. The overall sequence includes the activation of the imine by the acid, followed by aza-Prins cyclization to deliver the cationic specie $\mathbf{w w}$, this undergoes Friedel-Crafts reaction to afford the spirocyclic intermediate $\mathbf{v v}$, which re-aromatizes through a retro Friedel-Crafts fragmentation to give compound $\mathbf{x x}$. Three more steps, including demethoxycarbonylation, hydrolysis and deacetylation yielded Sespenine in $78 \%$ overall yield.

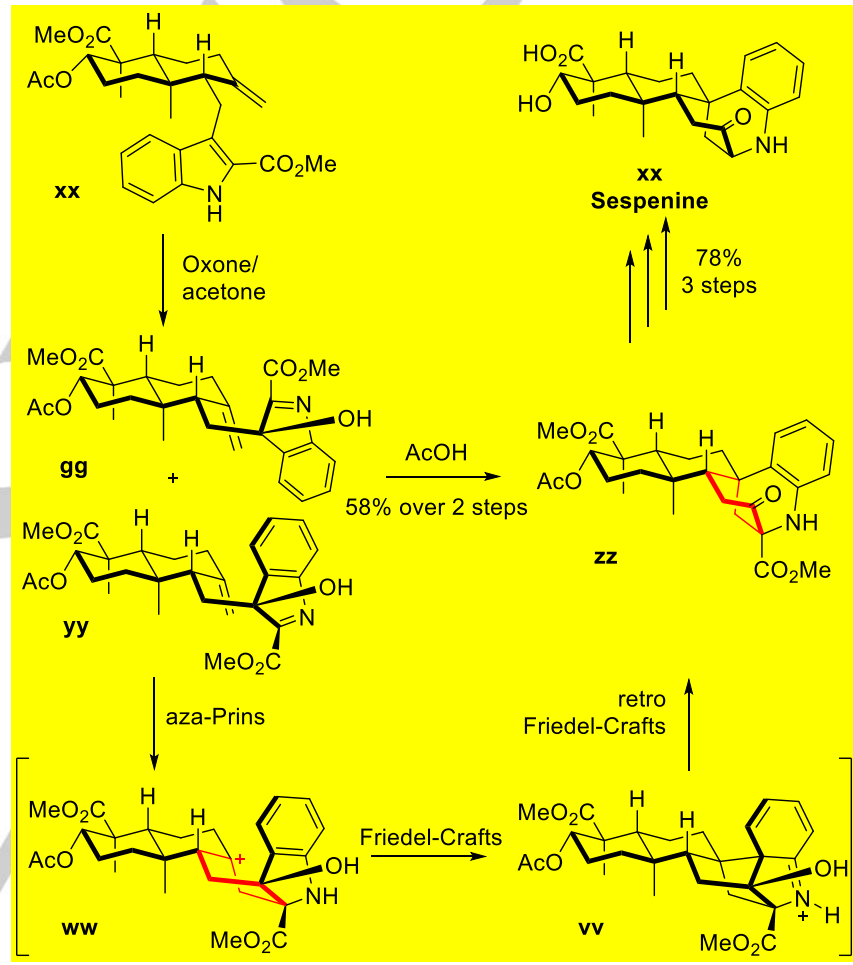

Scheme xx. Bioinspired total synthesis of Sespenine via an aza-Prins/FriedelCrafts/ retro Friedel-Crafts cascade.

$\mathrm{Li}$, Sun and co-workers reported the total synthesis of Notoamides F, I and R aa-cc, members of the prenylated indole alkaloids family, as well as Sclerotiamide, biosynthetically related to Notoamide $\mathrm{R}$ dd ${ }^{36}$ Their strategy rests on an oxidative aza-Prins cyclization to construct the bicyclo[2.2.2]diazaoctane ring, starting from the dipeptide $\mathbf{x x}$. Optimization of reaction conditions for the oxidation-cyclization step was necessary and finally treatment with $\mathrm{FeCl}_{3}$ in $\mathrm{CH}_{3} \mathrm{CN} / \mathrm{CH}_{2} \mathrm{Cl}_{2}$ afforded the desired bicycle yy in $67 \%$ yield, via the imine ww (Scheme $\mathbf{x x}$ ). With this compound in hands the authors successfully achieved the total synthesis of (+)-Notoamide I bb in $22 \%$ yield over five steps including a Grignard reaction followed by a Co catalyzed cycloisomerization to form the central 6 membered ring, and a $\mathrm{Cu}$ catalyzed propargylation followed by an allenyl Claisen rearrangement for the formation of the est oxygenated 6 
membered ring. Reduction of Notoamide I in the presence of DIBAL-H furnished (+)-Notoamide $\mathrm{R}$ cc in $85 \%$ yield, treatment of this latter with $\mathrm{AcOH} / \mathrm{MeOH}$ delivered $(+)$-Notoamide $\mathrm{F}$ aa in $95 \%$ yield. The rearrangement of $(+)$-Notoamide $R$ in the presence of an oxaziridine as oxidant afforded (-)-Sclerotiamide dd in $55 \%$ yield.

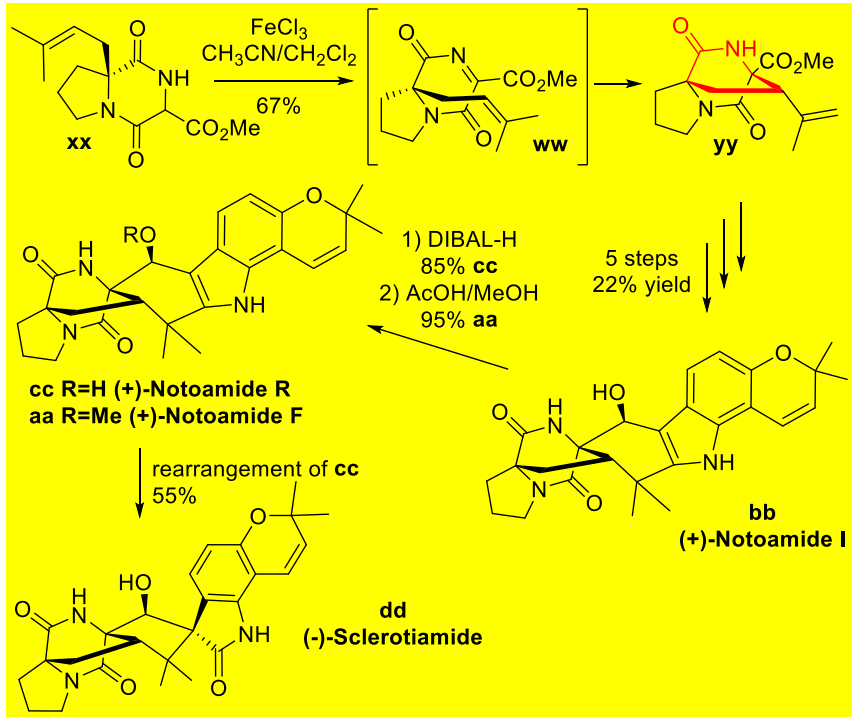

Scheme xx. Oxidative aza-Prins cyclization strategy for the synthesis of Notoamides F, I and R and Sclerotiamide.

Very recently Liu, Qin and co-workers reported the biologically inspired synthesis of four different types of diterpenoid alkaloid skeletons, including Atisine, Ajaconine, Denudatine and Hetidine, based on the biogenetic key Ajaconine subtype intermediate aa. ref The strategy to get this late stage intermediate includes a Corey-Seebach reaction between the known compounds $\mathbf{b b}$ and cc and an oxidative dearomatization/intramolecular Diels-Alder cascade to afford the Atisine subtype skeleton dd, followed by a $\mathrm{C}-\mathrm{H}$ oxidation process at the $\mathrm{C}-20$ position, together with an essential protection of the hydroxyl group as acetate (Scheme $\mathbf{x x}$ ). This Ajaconine subtype intermediate aa was prone to the key aza-Prins cyclization step realized in the presence of $\mathrm{BF}_{3} . \mathrm{Et}_{2} \mathrm{O}$ in $53 \%$ yield, in order to construct the C-20/C-14 bond of the hexacyclic Hetidine core $\mathbf{x x}$.

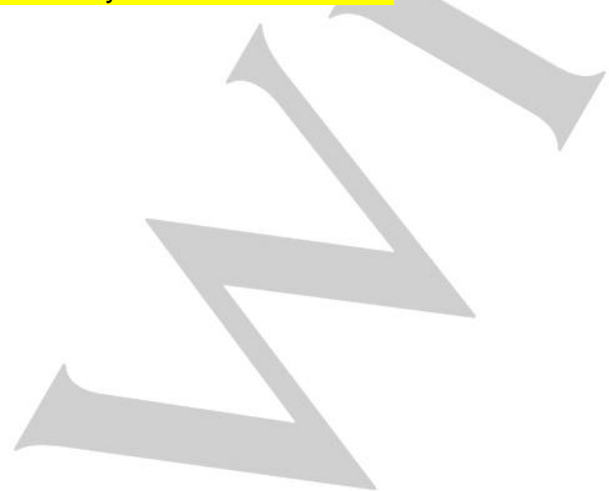

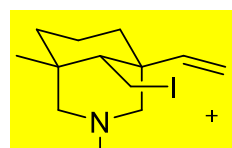

bb $\mathrm{CO}_{2} \mathrm{Me}$<smiles>C#[W]</smiles>

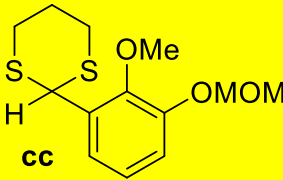

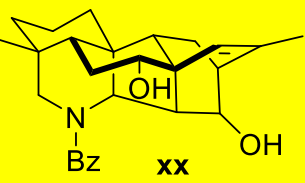

Hetidine skeleton

$\mathrm{BF}_{3} . \mathrm{Et}_{2} \mathrm{O} \uparrow$

$53 \%$

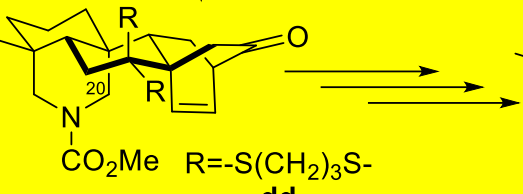

dd

Atisine subtype

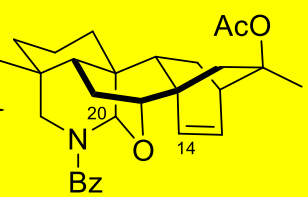

Ajaconine subtype
Scheme xx. Bioinspired synthesis of Hetidine skeleton via a late stage aza Prins cyclization of Ajaconine subtype core.

\section{Conclusion}

Aza-Prins and related cyclization reactions are now well established methods in organic synthesis. They can easily be used, directly, for the synthesis of simple piperidines as well as for bicyclic alkaloids for instance. This has been already demonstrated by excellent examples in this review article. For the natural products, as well as for the molecules designed as drugs or pharmacological tools, their preparation of optically pure form is required. The possible use of asymmetric synthetic methodologies, by using chiral pool approaches for instance, has been also clearly established in aza-Prins cyclization reactions. However, the asymmetric catalysis route remains to be developed, although the first successful entries in the catalytic asymmetric Prins reactions have appeared recently. ${ }^{37-38}$ The other fascinating aspect of the most recent research is this area is the evolution towards more and more complex molecules. This was made possible by the combination of aza-Prins cyclization with other reactions. Such tandem/ cascade/domino Prins-based reactions allowed the efficient preparation, in very few steps, of polycyclic very complex structures. It can be anticipated that this type of combination will be develop also in the future since it offers extremely powerful possibilities towards the synthesis of very challenging and important molecules. Therefore, we expect this review would trigger more developments in the utilization of these reactions in the total synthesis of natural, as well as non natural, bioactive molecules.

\section{Acknowledgements}

This research has been performed as part of the Indo-French "Joint Laboratory for Natural Products and Synthesis toward Affordable Health". We thank CNRS, CSIR and University of Rennes 1 for support of this research. 
Keywords: aza-Prins cyclization • natural products $•$ piperidine $•$ iminium ion $•$ acyliminium ion

[1] For reviews on the Prins cyclization reaction see: a) E. Arundale, L. A Mikeska, Chem. Rev. 1952, 52, 505-555; b) D. R. Adams, S. P. Bhatnagar, Synthesis 1977, 661-672; c) B. B. Snider In The Prins Reaction and Carbonyl Ene Reactions, Vol. 2; B. M. Trost, I. Fleming, C. H. Heathcock, Eds.; Pergamon Press: New York, 1991, 527-561; d) C. Olier, M. Kaafarani, S. Gastaldi, M. P. Bertrand, Tetrahedron 2010 , 66, 413-445; e) I. M. Pastor, M. Yus, Curr. Org. Chem. 2012, 16, 1277 1312; for reviews on the use of the Prins cyclization in total synthesis see f) L. E. Overman, L. D. Pennington, J. Org. Chem. 2003, 68, 7143 7157; g) P. A. Clarke, S. Santos, Eur. J. Org. Chem. 2006, 2045-2053; h) I. M. Pastor, M. Yus, Curr. Org. Chem. 2007, 11, 925-957; i) E. A. Crane, K. A. Scheidt, Angew. Chem. 2010, 122, 8494-8505; Angew. Chem., Int. Ed. 2010, 49, 8316-8326; j) X. Han, G.-R. Peh, P. E. Floreancig, Eur. J. Org. Chem. 2013, 1193-1208.

[2] a) G. B. Fodor, B. Colasanti, Alkaloids: Chemical and Biological Perspectives, Vol. 23 (Ed.; S. W.Pelletier); Wiley: New York, 1985, pp 1-90; For reviews on the synthesis of piperidines see: b) V. Baliah, $R$. Jeyarama, L. Chandrasekaran, Chem. Rev. 1983, 83, 379-423; c) P. D. Bailey, P. A. Millwood, P. D. Smith, Chem. Commun. 1998, 633-640; d) F. Couty, Amino Acids 1999, 16, 297-320; e) S. Laschat, T. Dickner Synthesis 2000, 1781-1813; f) M. G. P. Buffat, Tetrahedron 2004, 60 1701-1729.

[3] A. P. Dobbs, S. J. J. Guesné, Synlett 2005, 2101-2103.

[4] A. P. Dobbs, R. J. Parker, J. Skidmore, Tetrahedron Lett. 2008, 49, 827-831.

[5] R. M. Carballo, G. Valdomir, M. Purino, V. S. Martín, J. I. Padrón, Eur. J. Org. 2010, 2304-2313.

[6] O. Colin, C. Greck, D. Prim, C. Thomassigny, Eur. J. Org. Chem. 2014 7000-7005.

[7] B. V. S. Reddy, D. N. Chaya, J. S. Yadav, R. Grée, Synthesis 2012, 44, 297-303.

[8] T. Nakaya, A. Matsuda, S. Ichikawa, Org. Biomol. Chem. 2015, 13, 7720-7735.

[9] X. Liu, M. P. McCormack, S. P. Waters, Org. Lett. 2012, 14, 5574-5577.

[10] F. K. I. Chio, S. J. J. Guesné, L. Hassall, T. McGuire, A. P. Dobbs, J. Org. Chem. 2015, 80, 9868-9880.

[11] J. S. Yadav, P. Borkar, P. P. Chakravarthy, B. V. Subba Reddy, A. V. S. Sarma, S. J. Basha, B. Sridhar, R. Grée, J. Org. Chem. 2010, 75, 2081 2084.

[12] a) V. Parchinsky, A. Shumsky, M. Krasavin, Tetrahedron. Lett. 2011, 52, 7157-7160; b) V. Parchinsky, A. Shumsky, M. Krasavin, Tetrahedron Lett. 2011, 52, 7161-7163.

[13] B. E. Daniels, J. Ni, S. E. Reisman, Angew. Chem. 2016, 128, $3459-$ 3463; Angew. Chem., Int. Ed. 2016, 55, 3398-3402.

[14] A. Armstrong, Y. Bhonoah, S. E. Shanahan, J. Org. Chem. 2007, 72, 8019-8024.

[15] A. Armstrong, S. E. Shanahan, Org. Lett. 2005, 7, 1335-1338.

[16] Y. W. Son, T. H. Kwon, J. K. Lee, A.N. Pae, J. Y. Lee, Y. S. Cho, S.-J. Min, Org. Lett. 2011, 13, 6500-6503.

[17] Q. Chen, X. Huo, Z. Yang, X. She Chem. Asian J. 2012, 7, 2543-2546.

[18] B. M. Trost, W. Tang, J. Am. Chem. Soc. 2003, 125, 8744-8745.

[ref] J. Ploog, J. Pongs, S. Weber, W. Maison, Synthesis 2016, 48, DOI: $10.55 / \mathrm{s}-0036-1588071$
[19] a) S. Hanessian, M. Tremblay, Org. Lett., 2004, 6, 4683-4686; b) S. Hanessian, M. Tremblay, M. Marzi, J. R. Del Valle, J. Org. Chem. 2005 70, 5070-5085.

[20] S. Hanessian, M. Tremblay, J. F. W. Petersen J. Am. Chem. Soc. 2004, 126, 6064-6071

[21] K. Indukuri, R. Unnava, M. J. Deka, A. K. Saikia, J. Org. Chem. 2013, 78, 10629-10641.

[22] A. K. Saikia, K. Indukuri, J. Das, Org. Biomol. Chem. 2014, 12, 70267035.

[23] a) J. D. White, Y. Li, J. Kim, M. Terinek, Org.Lett. 2013, 15, 882-885; b) J. D. White, Y. Li, J. Kim, M. Terinek, J. Org. Chem. 2015, 80 11806-11817.

[24] Y. Xia, A. P. Kozikowski, J. Am. Chem. Soc. 1989, 111, 4116-4117.

[25] Y. Hirasawa, H. Morita, J. Kobayashi, Org. Lett. 2004, 6, 3389-3391.

[26] Y. Hirasawa, J. Kobayashi, Y. Obara, N. Nakahata, N. Kawahara, Y. Goda, H. Morita, Heterocycles 2006, 68, 2357-2364.

[27] a) B. L. Nilsson, L. E. Overman, J. R. de Alaniz, J. M. Rohde, J. Am Chem. Soc. 2008, 130, 11297-11299; b) R. A. Altman, B. L. Nilsson, L. E. Overman, J. R. de Alaniz, J. M. Rohde, V. Taupin, J. Org. Chem. 2010, 75, 7519-7534.

[28] a) T. Nishimura, A. K. Unni, S. Yokoshima, T. Fukuyama, J. Am. Chem. Soc. 2011, 133, 418-419; b) T. Nishimura, A. K. Unni, S. Yokoshima, T. Fukuyama, J. Am. Chem. Soc. 2013, 135, 3243-3247; c) S. Yokoshima, Chem. Pharm. Bull. 2013, 61, 251-257.

[29] a) D. Ma, Z. Zhong, Z. Liu, M. Zhang, S. Xu, D. Xu, D. Song, X. Xie, X She, Org. Lett. 2016, 18, 4328-4331; b) S. Xu, J. Zhang, D. Ma, D. Xu X. Xie, X. She, Org. Lett. 2016, 18, 4682-4685.

[30] a) J. Liu, R. P. Hsung, S. D. Peters, Org.Lett. 2004, 6, 3989-3992; b) J. Liu, J. J. Swidorski, S. D. Peters, R. P. Hsung, J. Org. Chem. 2005, 70, 3898-3902.

[31] H. Abe, S. Aoyagi, C. Kibayashi, Angew. Chem. 2002, 114, 3143-3146; Angew. Chem., Int. Ed. 2002, 41, 3017-3020.

[32] H. M. Lee, C. Nieto-Oberhuber, M. D. Shair, J. Am. Chem. Soc. 2008 130, 16864-16866

[33] A. Kamath, C.-H. Fabritius, C. Philouze, P. Delair, Org. Biomol. Chem. 2015, 13, 9834-9843.

[34] Y. Sun, R. Li, W. Zhang, A. Li, Angew. Chem. 2013, 125, 9371-9373; Angew. Chem., Int. Ed. 2013, 52, 9201-9204.

[35] Y. Sun, P. Chen, D. Zhang, M. Baunach, C. Hertweck, A. Li, Angew. Chem. 2014, 126, 9158-9162; Angew. Chem., Int. Ed. 2014, 53, 9012 9016.

[36] B. Zhang, W. Zheng, X. Wang, D. Sun, C. Li, Angew. Chem. 2016, 128, 10591-10594; Angew. Chem., Int. Ed. 2016, 55, 10435-10438.

[ref] X.-H. Li, M. Zhu, Z.-X. Wang, X.-Y. Liu, H. Song, D. Zhang, F.-P. Wang, Y. Qin, Angew. Chem. 2016, 128, 15896-15900; Angew. Chem., Int. Ed. 2016, 55, 15667-15671.

[37] C. Lalli, P. van de Weghe, Chem. Commun. 2014, 50, 7495-7498.

[38] a) G. C. Tsui, L. Liu, B. List, Angew. Chem. 2015, 127, 7814-7818; Angew. Chem., Int. Ed. 2015, 54, 7703-7706; b) L. Liu, P. S. J. Kaib, A Tap, B. List, J. Am. Chem. Soc. 2016, 138, 10822-10825. 


\section{MICROREVIEW}

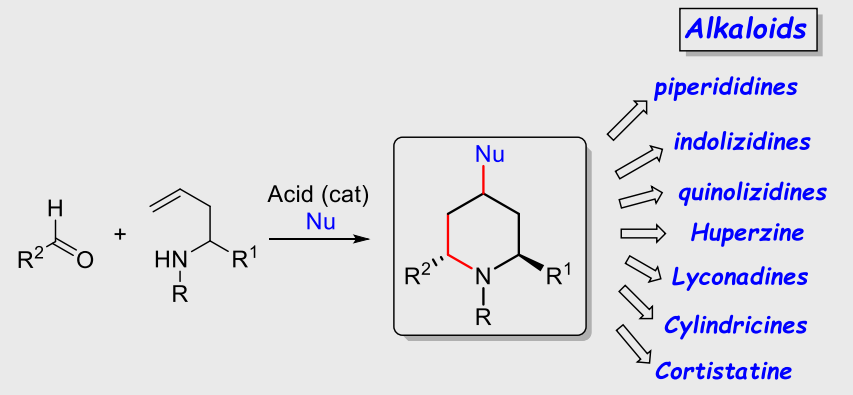

Natural products Synthesis

B. V. Subba Reddy, ${ }^{*}$ Preethi Narayanan Nair, Aneesh Antonyl Claudia Lalli, ${ }^{*}$ and René Grée*

Page No. - Page No.

Aza-Prins Reaction in the Synthesis of Natural Products and Analogues

Aza-Prins, and related reactions, have demonstrated high efficiencies in the direct synthesis of piperidine-, indolizidine- and quinolizidine-type alkaloids. More recently, new strategies combining aza-Prins in sequence with other reactions have proved to be very powerful in the preparation of complex polyheterocyclic natural products and bioactive molecules. 